\title{
Influence of climate shifts on decadal variations of surface solar radiation in
} Alaska

Chiacchio, Marc ; Ewen, Tracy ; Wild, Martin ; Arabini, Elena

\begin{abstract}
From past studies it has been known that the Pacific Decadal Oscillation (PDO) shifted toward a positive mode in 1976 and a new climate regime occurred that produced a warming of the mean annual and seasonal temperatures and associated increases in cloud cover and precipitation in the North Pacific including Alaska. In this study, this climate shift is examined with regard to the variations in surface solar radiation before and after 1976 during the period 1961-2005. The results show greatest changes occurring in the southeast region in winter with a significant rise of $1.67 \% \mathrm{yr}$
\end{abstract}

DOI: https://doi.org/10.1029/2009JD012533

Posted at the Zurich Open Repository and Archive, University of Zurich

ZORA URL: https://doi.org/10.5167/uzh-36711

Journal Article

Published Version

Originally published at:

Chiacchio, Marc; Ewen, Tracy; Wild, Martin; Arabini, Elena (2010). Influence of climate shifts on decadal variations of surface solar radiation in Alaska. Journal of Geophysical Research, 115(D00D21):1-19.

DOI: https://doi.org/10.1029/2009JD012533 


\title{
Influence of climate shifts on decadal variations of surface solar radiation in Alaska
}

\author{
Marc Chiacchio, ${ }^{1}$ Tracy Ewen, ${ }^{1}$ Martin Wild, ${ }^{1}$ and Elena Arabini ${ }^{2}$ \\ Received 23 May 2009; revised 22 August 2009; accepted 7 October 2009; published 4 March 2010.
}

[1] From past studies it has been known that the Pacific Decadal Oscillation (PDO) shifted toward a positive mode in 1976 and a new climate regime occurred that produced a warming of the mean annual and seasonal temperatures and associated increases in cloud cover and precipitation in the North Pacific including Alaska. In this study, this climate shift is examined with regard to the variations in surface solar radiation before and after 1976 during the period 1961-2005. The results show greatest changes occurring in the southeast region in winter with a significant rise of $1.67 \% \mathrm{yr}^{-1}$ during 1961-1975 before the shift and a nonsignificant decline of $-1.07 \% \mathrm{yr}^{-1}$ during $1977-1991$ after the shift. In addition to the variations in solar radiation that occurred after 1976, the PDO and the solar radiation time series show common changes around 1989 and 1998. Thus, these two variables are compared to assess the strength of their relationship. The results show a good to moderate correlation with a maximum found in winter in Big Delta (interior region). The Pacific North American (PNA) circulation pattern is also strongly correlated with the solar radiation, with a maximum in winter in Anchorage (south-central region). In addition, a close relationship is found between cloud cover and solar radiation, particularly in the south-central and southwest regions. These results suggest that circulation patterns and associated cloud cover changes may play a large role, especially during wintertime, in the variations in the surface solar radiation in these regions of Alaska.

Citation: Chiacchio, M., T. Ewen, M. Wild, and E. Arabini (2010), Influence of climate shifts on decadal variations of surface solar radiation in Alaska, J. Geophys. Res., 115, D00D21, doi:10.1029/2009JD012533.

\section{Introduction}

[2] The climate shift that occurred in the North Pacific in the winter of 1976 has been referred to as the 'Great Pacific Climate Shift', which has had large impacts on different climate, biological, and ecological variables. Particularly in the Alaskan region this climatic shift has had tremendous impacts on the climate system, such as large increases in winter and spring temperatures [Hartmann and Wendler, 2005]. In addition, there has been an influence from the El Niño-Southern Oscillation (ENSO) signal with regards to El Niño and La Niña on the wintertime temperatures [Papineau, 2001].

[3] Cooler than average sea surface temperatures (SST) were discovered during the 1960s in the eastern North Pacific with warmer temperatures in the central North Pacific [Namias, 1969]. After this discovery the teleconnection between the central and eastern SST anomalies was explored, which set the stage for further investigations on large-scale seasonal ocean-atmosphere interactions. Since the 1990s,

\footnotetext{
${ }^{1}$ Institute for Atmospheric and Climate Science, ETH Zurich, Zurich, Switzerland.

${ }^{2}$ Department of Mechanical and Civil Engineering, University of Modena and Reggio Emilia, Modena, Italy.

Copyright 2010 by the American Geophysical Union. 0148-0227/10/2009JD012533\$09.00
}

studies that focused on this pattern of cool and warm SSTs in the Pacific basin have now shown that this is a pattern that can change and reverse itself by an abrupt shift, which can cause a new climate regime to occur [Graham, 1994; Miller et al., 1994; Trenberth and Hurrell, 1994; Mantua et al., 1997; Hare and Mantua, 2000; Peterson and Schwing, 2003]. It has been proposed that the main cause of the 1976 shift was due to a forcing from anomalies of tropical Pacific SSTs on the circulation in the North Pacific [Trenberth, 1990; Graham, 1994], which is supported from modeling experiments [Blackmon and Lee, 1984; Graham, 1994]. These experiments showed that an eastward shift and intensified Aleutian low in winter and autumn formed over the North Pacific as a result of these SST anomalies. After the persistence of this low-pressure system in Alaska, which is also confirmed in other studies [Trenberth, 1990; Papineau, 2001; Hartmann and Wendler, 2005], there was an advection of warmer and moister air over the North Pacific during 1977 to 1988 [Trenberth, 1990]. Associated with these temperature changes were variations in surface winds, sea level pressure and the North Pacific Ocean currents, which have profound effects on the atmosphere and ocean.

[4] Additional research has explored alternative causes of these abrupt changes in the climate with changes in atmospheric waves [Trenberth, 1990]. These waves are known to be brought on by the orography and the diabatic heating between the land and sea; however, according to this study, 
greater land-sea contrasts would be needed to produce these types of waves with the Aleutian low that is observed. A coupled ocean-atmosphere model and observations were used to explain the mechanisms that produce the SST patterns in the North Pacific, and it was found that about one third of this Pacific variability is in the air-sea interaction between the low-pressure system, such as the Aleutian low, and the subtropical gyre circulation in the North Pacific [Latif and Barnett, 1996]. In view of a similar study, this circulation in the ocean was found to be an additional forcing on the shift [Miller et al., 1994].

[5] It has been known since the early 20th century that there exist decadal climate variations in the North Pacific [Walker and Bliss, 1932]. Moreover, with the increased availability of data to analyze on longer temporal scales, much work has been done in this area to further understand the resulting effects these climate shifts have on the climate system. As previously mentioned, impacts of the climate changes also influence biological variables, which was the case with the Pacific salmon production. Mantua et al. [1997] found that while numbers of salmon were becoming more abundant in Alaska during the 1960s and early 1970s, those in the Pacific Northwest dwindled and found it to be connected to the alternating pattern shift in the Pacific. In fact, this salmon production pattern was found to vary on an interdecadal period in the Pacific occurring about every 20 30 years. This pattern is now referred to as the Pacific Decadal Oscillation (PDO) [Mantua et al., 1997]. This oscillation they found, using North Pacific SST pattern time series, reverses in polarity from warm (positive mode) to cold (negative mode). During the positive phase of the PDO the SSTs are cooler in the central North Pacific and warmer in the eastern North Pacific; the reverse is true for the negative phase. There was also an increase in winter storms in the North Pacific [Graham and Diaz, 2001] and an anomalous weakening of coastal upwelling [Chhak and Di Lorenzo, 2007] during the positive mode. The PDO during 19251946 was positive, then negative during 1947-1976, and then positive after 1977. In addition, during a few years within these climate regimes the PDO changed polarity with a positive phase occurring during 1958-1961 and a much stronger negative mode during 1989-1991. The change in polarity that occurs when the PDO reverses up to a few years is also referred to as a shift [Mantua et al., 1997]. When the PDO was in its positive mode, air temperatures in the Gulf of Alaska were warmer on average and the reverse was also true with cooler temperatures when the PDO was in its negative phase [Zhang et al., 1997; Mantua et al., 1997; Papineau, 2001; Hartmann and Wendler, 2005]. A connection of the PDO with the atmosphere was found with $500 \mathrm{hPa}$ geopotential height anomalies where troughs were more common during the positive mode of the PDO and ridges generally found during a negative phase [Bond and Harrison, 2000]. Earlier this was defined as the Pacific North American (PNA) pattern [Wallace and Gutzler, 1981].

[6] With much focus placed on the climate shift of 1976 with regard to the phases of the PDO, PNA, and the El Niño-Southern Oscillation (ENSO), and its impacts on many atmospheric and oceanic variables in North America and the North Pacific [Trenberth and Hurrell, 1994; Graham, 1994; Zhang et al., 1997; Bond and Harrison, 2000; Papineau, 2001; Hartmann and Wendler, 2005; Ewen et al., 2008], this study continues in this direction but sheds new light on the influence these climate shifts have on the decadal changes in the all-sky downward surface shortwave radiation (hereinafter as DSW) in Alaska. This current work reflects on the decadal variations of the DSW in past studies with a decrease (dimming) found at sites from around the world [Ohmura and Lang, 1989; Russak, 1990; Dutton et al., 1991; Stanhill and Kalma, 1995; Abakumova et al., 1996; Gilgen et al., 1998; Liepert, 2002, Liepert and Kukla, 1997; Stanhill and Cohen, 2001]. Also, it makes reference on the increase (brightening) after the mid-1980s discovered from global sites and satellite-derived DSW over the land [Wild et al., 2005; Pinker et al., 2005; Gilgen et al., 2009; Wild, 2009].

[7] The results reported here from the DSW trends since the 1960s through the 1990s found in certain regions of Alaska do not display the typical dimming and brightening phenomena. We mainly attribute the cause of the decadal variations in the DSW in this geographical region to the cloud cover and circulation patterns that dominate the North Pacific. Although other factors, such as aerosols could also be contributing to these changes, we find that the cloud cover and circulation patterns may be playing a large role, especially during winter. This was also the case in other studies [Sanchez-Lorenzo et al., 2008; Stjern et al., 2009; Chiacchio and Wild, 2010] where circulation patterns and associated cloud cover contributed to the changes in all-sky DSW during winter and autumn in Europe.

[8] The aim of this work is to show how much of an influence the climate signal, PDO, and the circulation pattern, PNA, have on these changes in DSW. In addition, the trends of the DSW are computed before and after the climate shift of 1976 to quantify their influence attributed to the circulation patterns for each climate region of Alaska. Cloud cover changes will also be examined so that they can be compared and contrasted with the DSW and an assessment can be made as to how much the DSW changes are also influenced by the clouds.

\section{Data and Methods}

[9] The source of the solar radiation data for Alaska was from the National Solar Radiation Database (NSRDB) produced by the National Renewable Energy Laboratory (NREL) [Maxwell, 1998]. This database consists of hourly total, diffuse, and direct normal solar radiation fluxes produced from the METSTAT (Meteorological/Statistical) model, which was developed specifically to estimate hourly surface energy fluxes in the United States when measurements were not available. Input variables include total and opaque cloud cover, precipitable water vapor, aerosol optical depth, surface albedo, and snow cover. Additional parameters are monthly values of ozone and observations of weather conditions (e.g., rain, snow, fog). The total and opaque cloud cover amounts are used in this model to calculate the cloud optical depths with a simple opaque cloud transmittance algorithm, which corrects for zenith angle effects (see Maxwell [1998] for more details). The precipitable water vapor data were taken from radiosondes and derived from other measurements, such as from surface temperature, relative humidity, and pressure when no radiosonde data were available. Because of large uncertainties found in the 


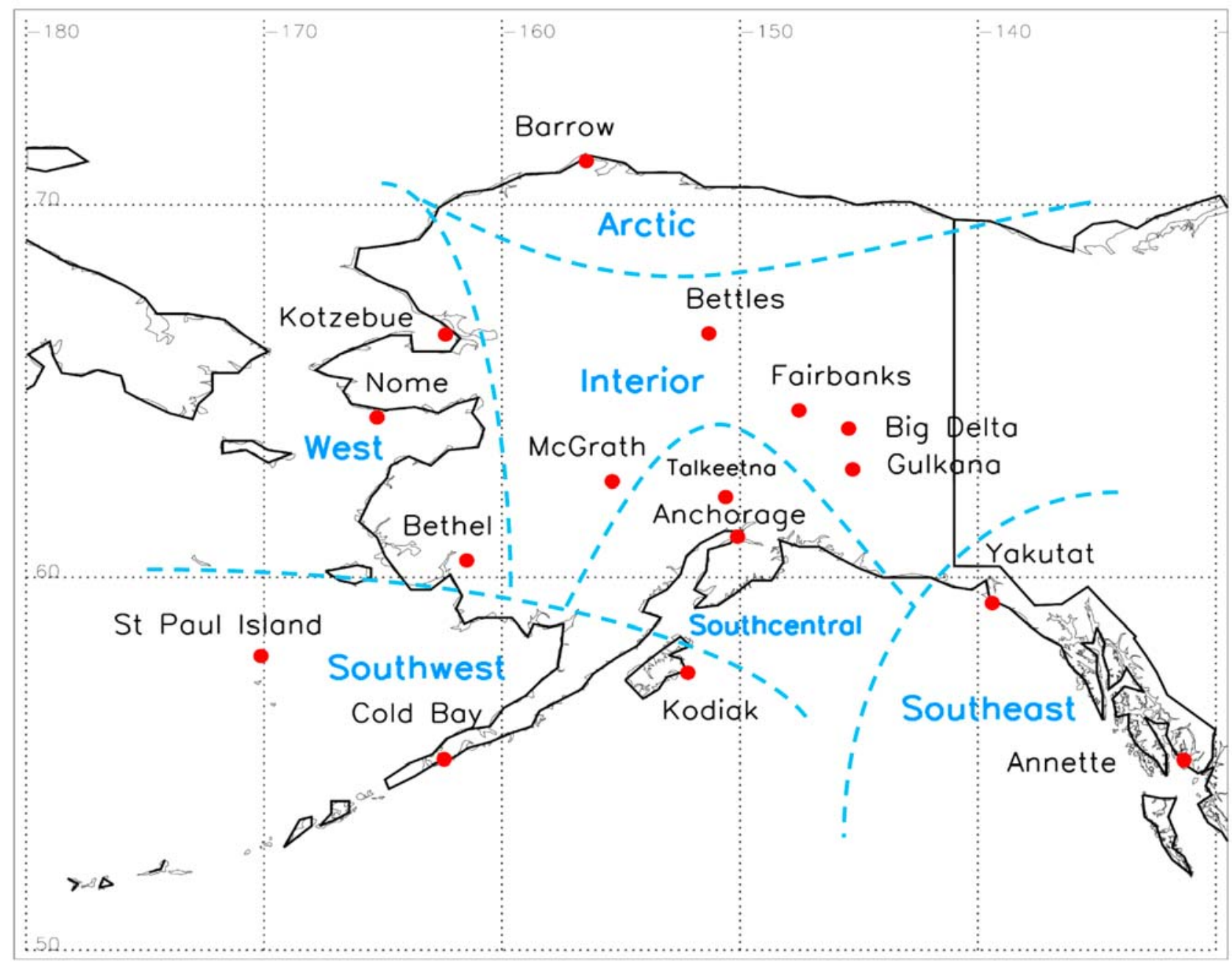

Figure 1. Locations of model-derived all-sky downward surface shortwave radiation in Alaska with each climate region indicated.

measured aerosol optical depths and a small number of stations with limited periods of time, a clear-sky algorithm was developed and applied in the METSTAT model. As input to this algorithm, the direct normal component of the fluxes was used from available stations during clear-sky conditions. This allowed direct normal transmittances to be computed and broadband aerosol optical depths derived using an inversion of Beer's law. An additional algorithm, which incorporated a look-up table of monthly average albedos when the snow depth was less than three centimeters, was used in the model to accurately determine the surface albedo. When the snow depth was less than or equal to three centimeters an empirical relationship was considered that accounted for surface roughness. The database after 1990 includes an updated version of the model, which was completed in April 2007 and was produced by NREL in collaboration with other governmental and educational organizations [Wilcox et al., 2007]. The main differences in the updated version of the model are in the cloud cover measurements and in the estimate of the aerosol optical depth. Automated cloud cover observations were used to derive total and opaque cloud cover while the aerosol optical depths were derived from a combination of surface sun photometry and satellite data. This approach in the updated version to derive the aerosol optical depth overall has a better accuracy than the older version of the radiation model. For a more detailed description of the updated version of this model see Wilcox et al. [2007].

[10] To evaluate the derived surface fluxes from the model, validation was performed according to a seasonal and regional basis by Maxwell [1998]. In a comparison of these estimated fluxes to measurements from 28 stations, the average monthly mean differences were $4.3 \mathrm{~W} \mathrm{~m}^{-2}$ with a standard deviation of $16.4 \mathrm{~W} \mathrm{~m}^{-2}$. As a result from the comparison of the modeled to measured data for the total solar radiation according to six geographical regions, it was the winter season in the Northwest region that had the lowest biases. In fact, it was found that $90 \%$ of the monthly hourly means of these derived fluxes were within $7.5 \%$ from the measured fluxes. Additional validation is conducted on five Alaskan stations [Dissing and Wendler, 1998]. From these sites, annual cycle comparisons between measured and modeled DSW values were made, which showed underestimations mostly during the spring, and was especially pronounced in Barrow. 
[11] From the model-derived DSW we used the time series starting from 1961 until 2005 in Alaska. Figure 1 is a map that displays the locations of the model-derived DSW used in this study with each region defined according to Hartmann and Wendler [2005]. From the time period chosen for the analysis, we evaluated the changes in the DSW before and after the climate shift of 1976 . Two periods were selected with the first one beginning in 1961 until 1975 and the second period from 1977 to 1991. This allowed for an equal amount of temporal coverage for determining the trends and to further evaluate the effect from the shift in the climate regime after 1976. The trends detected for the DSW included those from the annual and seasonal mean time series, which was computed from a linear regression model to determine a firstorder best fit line. The confidence intervals were determined by applying the Student's $t$ test with a $p$ value equal to 0.05 and the standard error of the best fit line. The statistical significance at the $95 \%$ confidence level can then be made when the null hypothesis is rejected or when the trend line is different from zero. The statistical significance of the confidence levels at $95 \%$ was also supported by the autocorrelation, which was accounted for to detect the randomness in the data set for different time lags. If the autocorrelation was near zero for all time lags and within the $95 \%$ confidence limits, then the time series was random and validated the statistical significance.

[12] In addition, annual and seasonal mean correlations were determined between the DSW and the indices. These indices correspond to the climate signal of the PDO and the circulation pattern of the PNA. The correlations were computed from the Pearson correlation coefficient both for the 1961-2005 and the 1961-1990 periods. Statistical significance at the $95 \%$ confidence level of these correlations was first determined by using

$$
t=r \sqrt{\frac{(n-2)}{\left(1-r^{2}\right)}},
$$

where $r$ is the correlation coefficient and $n$ is the total number of points. The critical $t$ value from the Student's $t$ test at the $95 \%$ confidence level was determined and compared to this $t$ value from equation (1) to see whether the null hypothesis, i.e., where no relationship exists between these two variables, was rejected. The period 1961-1990 was analyzed to determine if a change occurred in the strength of the relationship of the above parameters, which might give some indication about the extent of the influence of the PDO and/or PNA during these selected periods of interest.

[13] Cloud data in this study were taken from the Alaska Climate Research Center of the Geophysical Institute, University of Alaska Fairbanks. For consistency, the same periods from the DSW analysis were chosen, but not all sites were included from the cloud data set due to incomplete coverage for some of the stations. These cloud observations were made from certified observers and have passed quality checks. They were recorded every hour according to the standard meteorological code from 0 okta to skyobscured cloud cover. Data with gaps of more than $10 \%$ of daily means were filled with monthly climatological values for that particular station. Thus, if more than 3 days were missing within any month, a monthly climatological mean value was used for that station. Moreover, Dissing and Wendler [1998] show a comparison of these surface-based cloud cover observations with ceilometer-based measurements for Barrow and Barter Island. As a result, the discrepancies of the cloud cover between these two data sets are mostly due to the different fields of view between a surface observer and a ceilometer and the different periods represented in the analysis; however, they show similar annual mean cycles. In addition, Schweiger and Key [1992] compare these surface-measured cloud cover data with two satellite cloud data sets, namely the International Satellite Cloud Climatology Project (ISCCP) and Nimbus-7. They find the satellite cloud cover to be $5-35 \%$ less than the surface-based cloud cover. The cloud amounts from surface observers are usually larger than those derived from satellites because of their differences in viewing geometries [Schweiger and Key, 1992; Chiacchio, 2001]. We chose the cloud cover from surface observations because their station locations were exactly matched with the locations of the DSW estimates. When satellite-derived cloud cover is used, spatial errors can arise when the satellite-derived averaged cloud cover in a grid box may not well represent the station measurement of the cloud cover [Chiacchio et al., 2002; Chambers et al., 2004].

[14] From the hourly observations, monthly and annual means were computed to determine the annual and seasonal trends using linear regression analysis and significance tests at the $95 \%$ level. The method used to compute the confidence levels and determine the statistical significance of these trends was similar to the method used in the DSW trend analysis. The cloud cover measurements were also correlated with the DSW using the same statistical significance test applied as before at the 95\% level to assess their relationship. A 5 year running average was used to compute the low-frequency variability and determine the long-term role the clouds have on the changes in DSW. In addition, the cloud cover decadal changes were correlated with the indices of the PDO and PNA during 1961-2005 and the shorter period from 1961 to 1990 to quantify the relationships between them.

[15] The monthly PDO index used to compute the correlation between the DSW and PDO and cloud cover and PDO for the annual and seasonal mean series was obtained from the Joint Institute for the Study of the Atmosphere and Oceans at the University of Washington. This index represents the leading principle component of the monthly SST anomalies in the North Pacific Ocean poleward of $20^{\circ} \mathrm{N}$ [Mantua et al., 1997]. From this index annual and seasonal means were constructed for the whole analysis period (1961-2005). The PNA index was from the NOAA Climate Prediction Center, and was constructed from the rotated principle component applied to $500 \mathrm{hPa}$ geopotential height anomalies in the region $20^{\circ} \mathrm{N}-90^{\circ} \mathrm{N}$. [Barnston and Livezey, 1987].

\section{Results}

\subsection{PDO/PNA Index}

[16] Figure 2 shows the temporal evolution of the annual mean PDO index from 1961 to 2005 . The shift that occurred from a negative to a positive mode in 1976 was clearly evident in the unsmoothed time series. The exact month when 


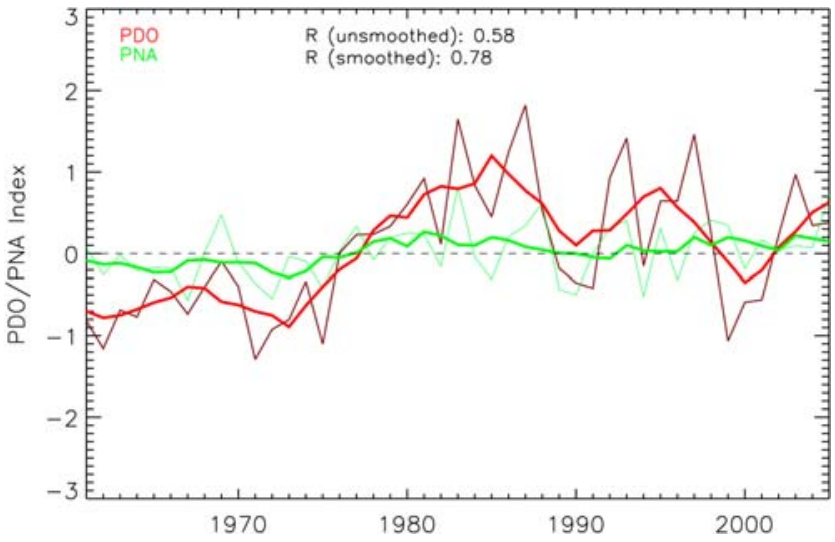

Figure 2. Time series of the annual mean Pacific Decadal Oscillation (PDO) (light red line) and the Pacific North American (PNA) index (light green line) from 1961 to 2005. A 5 year moving average is applied to both the PDO (dark red line) and PNA (dark green line) time series.

this shift occurred was during June 1976 from the monthly mean time series (not shown). In the annual mean time series, the index values increased from -1.10 during 1975 to 0.01 in 1976. It has been proposed that the positive phase of the PDO lasted from about 1977 to about 2001 [Hartmann and Wendler, 2005], but within that period the annual mean time series showed other additional characteristics that are important to mention. From Figure 2, there clearly were other minor shifts present, though less prominent than the one in 1976, which occurred in 1989 where the index has fallen from 0.53 in 1988 to -0.18 in 1989 and in 1999 where the index decreased from 0.25 in 1998 to -1.06 in 1999 .

[17] For the winter (DJF) mean time series of the PDO (Figure 3) the shift occurred during the winters of 1975 and 1976 with index values increasing from -1.53 to 1.32 . The difference of the indices from these two winters was greater than the difference from the shift found in the annual mean series. A minor change in index found before from the annual time series was again present during winter and occurred between the winters of 1988 and 1989 with index values from 1.15 to -0.8 , respectively. The second additional shift occurred between 1998 and 1999 with index values that fell from 1.02 to -0.47 . Moreover, by comparing the winter mean to the annual series for these two additional shifts during 1989 and 1999, the winter mean series showed a much more pronounced change in the indices.

[18] In addition to the PDO, the annual (Figure 2) and winter mean (Figure 3) series of the PNA indices were also analyzed. The shift of 1976 was almost nonexistent in the annual mean evolution of the PNA, but their relationship between these indices was still strong and was more evident in the winter average. For the unsmoothed original values of the indices, the correlation was 0.58 , which increased to 0.78 using a 5 year moving average. Although the PNA affects climate in North America over most of the year, temperature variations in the Northwest and Southwest United States are strongly related to the PNA in winter and spring. For the winter series of the PNA, there was an indication for a shift that occurred in the late 1970s with minor changes that occurred around 1989 and 1999. More- over, the correlation was greater during winter between the PNA and PDO with a value of 0.69 for the original series and 0.80 for the smoothed series. All correlations for the annual and winter mean time series showed a statistical significance at a confidence level greater than $95 \%$.

\subsection{Regional Surface Solar Radiation and Cloud Cover Trends}

[19] The annual and seasonal mean DSW for the six regions of Alaska (southeast, south-central, southwest, west, interior, and Arctic) are shown in Figures 4-9. The red line represents the annual or seasonal average series and the black line is the 5 year moving average. Though these time series showed interannual variability, the overall characteristic of these regions (except the Arctic) displayed a decrease in DSW during the late 1970s to the 1990s, which closely followed the variability of the PDO time series. Particularly for the southeast region in winter (Figure 4), the sharp decrease that occurred in the late 1970s was apparent, which is in agreement with the winter time series of the PDO, though they are anticorrelated with one another. Additional changes that were also evident in almost all of the time series was during 1989 and 1998, which is in line with the changes that occurred in the PDO index.

[20] In the south-central region the changes in DSW during 1976 and 1989 were quite strong but only in the winter season (Figure 5). The sharp decrease around 1998 for this region was apparent in all time series with the strongest signal in spring (MAM), summer (JJA), and in the annual mean series. Also, after the year 2000 a strong reversal in the DSW occurred in all seasons and in the annual. For the southwest region (Figure 6), the sharp decrease during the late 1970s was present in all time series with a much stronger change in 1989, especially in winter. After about 1990 the DSW became more stable throughout the period.

[21] The next region is located in the western part of Alaska, which showed similar characteristics among all the seasons as well as in the annual mean series (Figure 7). The DSW decreased in the late 1970s until the 1990s with another change found only in winter during 1989. Throughout the rest of the 1990s a sharp decrease occurred in 1998 and was easily visible in all the time series.

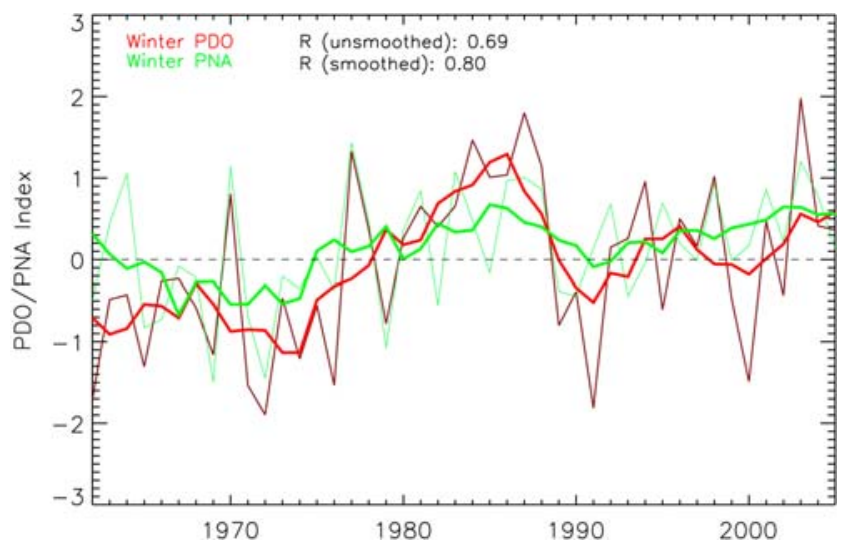

Figure 3. As in Figure 2 but for the winter (DJF) mean Pacific Decadal Oscillation (PDO) and the Pacific North American (PNA) index. 

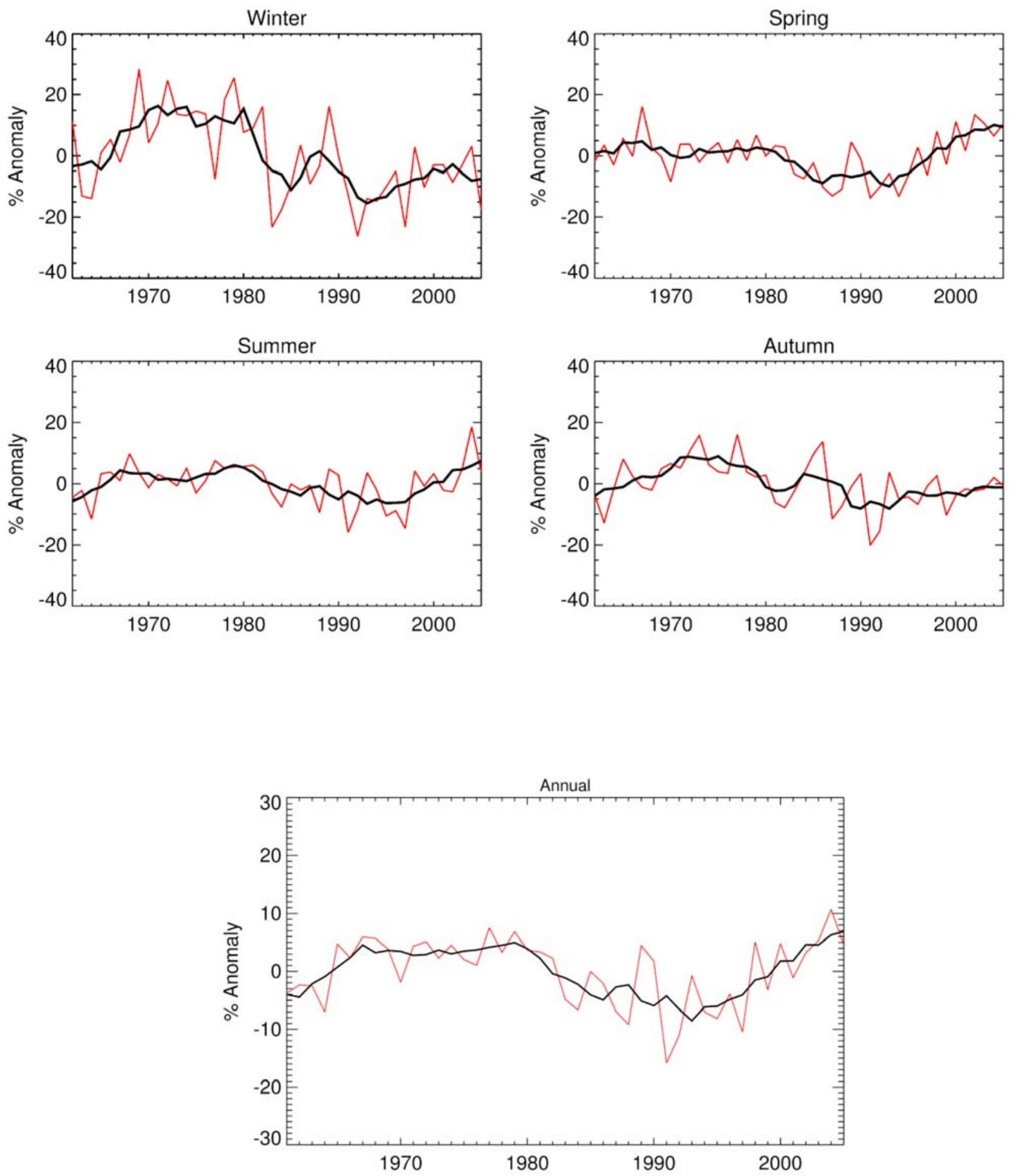

Figure 4. Time series of (top and middle) seasonal and (bottom) annual mean model-derived all-sky downward surface shortwave radiation (red line) with 5 year moving averages (black line) for the southeast region.

[22] The interior region of Alaska only showed downward changes of the late 1970s occurring in winter; however, the 1998 change strongly occurred during the spring, summer, and in the annual mean series (Figure 8). Finally, for the Arctic region the typical decrease in DSW from the late 1970s through the 1990s did not occur (Figure 9). What was apparent in this region was the sharp decrease in DSW that occurred in the late 1980s in all the time series except in winter.

[23] To investigate the impact that the 1976 climate shift had on the quantitative changes in the DSW, trends were computed before and after the shift (Table 1). The greatest 

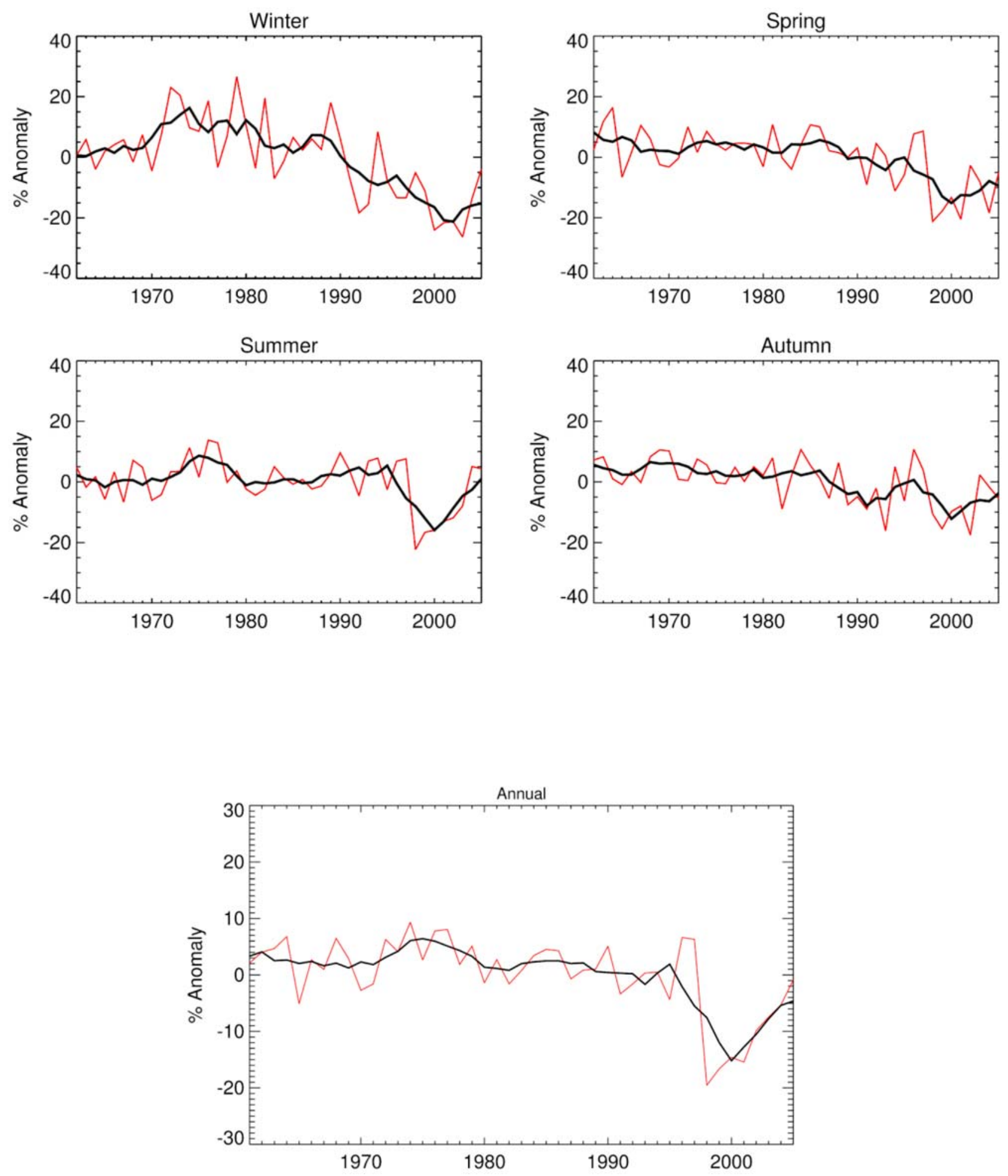

Figure 5. As in Figure 4 but for the south-central region.

changes occurred in the southeast region in winter during $1961-1975$ with a trend of $1.67 \% \mathrm{yr}^{-1}$ before the shift and $-1.07 \% \mathrm{yr}^{-1}$ during $1977-1991$ after the shift. Almost all trends before the shift in winter, except in the Arctic, were statistically significant at the $95 \%$ confidence level. Followed by the southeast, the southwest and the western regions displayed the greatest changes occurring in the summer and autumn (SON) with almost all trends in these two regions being statistically significant. The least amount of change occurred in the south-central and interior region and almost one half of the trends from all the seasons in this region were statistically significant. In general, from all of the regions, the spring and summer showed the least amount of change from the trends before and after the shift. Also, all regions and time periods (except Arctic winter, and the southcentral spring, summer, and autumn) showed the same 

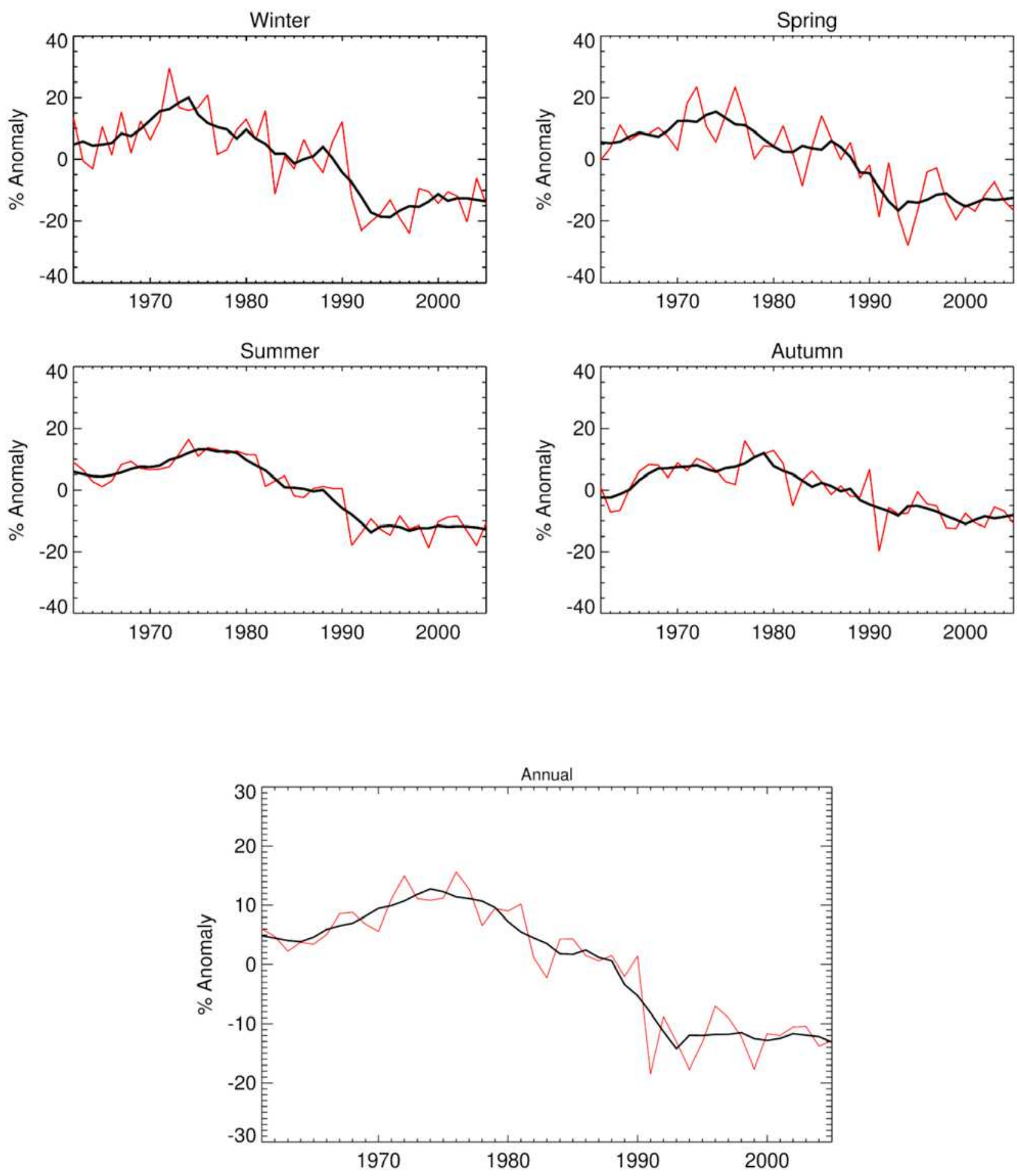

Figure 6. As in Figure 4 but for the southwest region.

reversal in trend with positive values before and negative values after the shift with maximum changes at the shift occurring in winter. The regions with exceptions, however, still showed a decrease in the DSW after the shift.

[24] Figures 10-16 show the temporal evolution of cloud cover for each station that had available data for the entire 1961-2005 period. In Figure 10 the time series of the cloud cover is shown for the Annette station, which is located in the southeast region of Alaska. Large increases were found until about 1988 for all seasons (only winter is shown) as well as in the annual mean except in the winter and spring, which was in agreement with the variability of the PDO time series. The changes that occurred in cloud cover in 1998 were also evident in all the time series but from this point onward, it showed disagreement in phase between the cloudiness and the DSW; the cloud cover decreased while the DSW increased. 

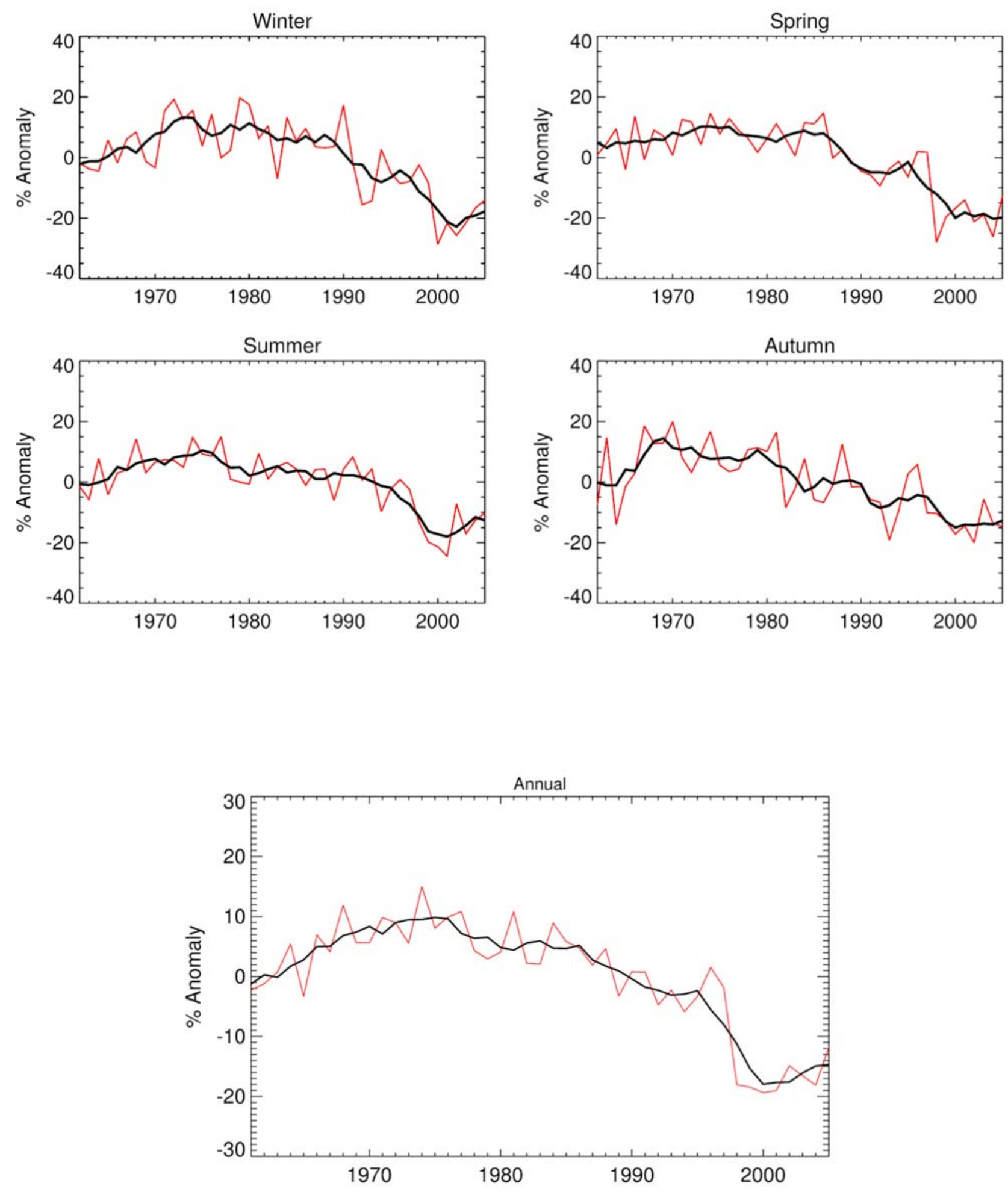

Figure 7. As in Figure 4 but for the western region.

Moreover, compared to all the time series of the DSW, the interannual variability in cloudiness was far greater.

[25] The Anchorage site (south central) displayed the increase in cloud cover during the 1980s during winter (Figure 11) and summer only. The 1989 change was also clearly visible in the annual, spring, and summer time series. All of the time series showed the change that occurred in
1999 with the strongest signals occurring in the annual, spring, and summer. In addition, there existed a high anticorrelation between the annual mean DSW and the cloud cover; the correlation was -0.70 for the original time series and -0.73 for the 5 year moving average or smoothed series, which were both statistically significant. The highest correlation was found in the autumn season with -0.72 for 

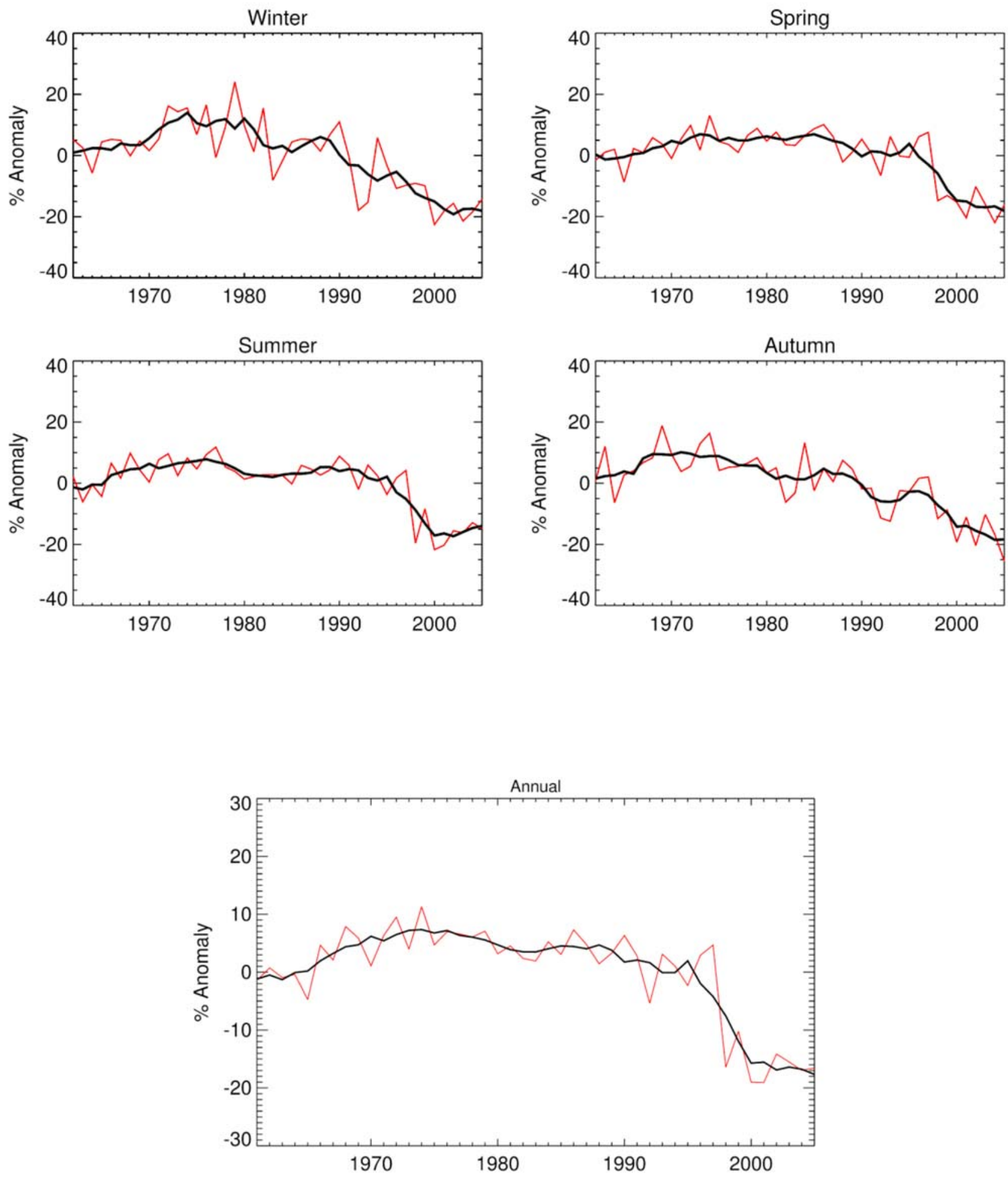

Figure 8. As in Figure 4 but for the interior region.

the unsmoothed series and -0.80 for the smoothed series, followed by the summer and winter and lastly the spring. All correlations were statistically significant.

[26] Another site that is included in the south-central region is Talkeetna (Figure 12). This site was clearly affected by the changes that occurred in the PDO during the late 1970s in winter and also in spring. The annual mean time series clearly revealed the change during 1989 followed by winter and then spring. The change at this time was evident but was not as strong as the one in Anchorage. Also, the correlation between these two parameters, though significant, was not as high as the one found in the Anchorage site, so there was less agreement for all time series. 

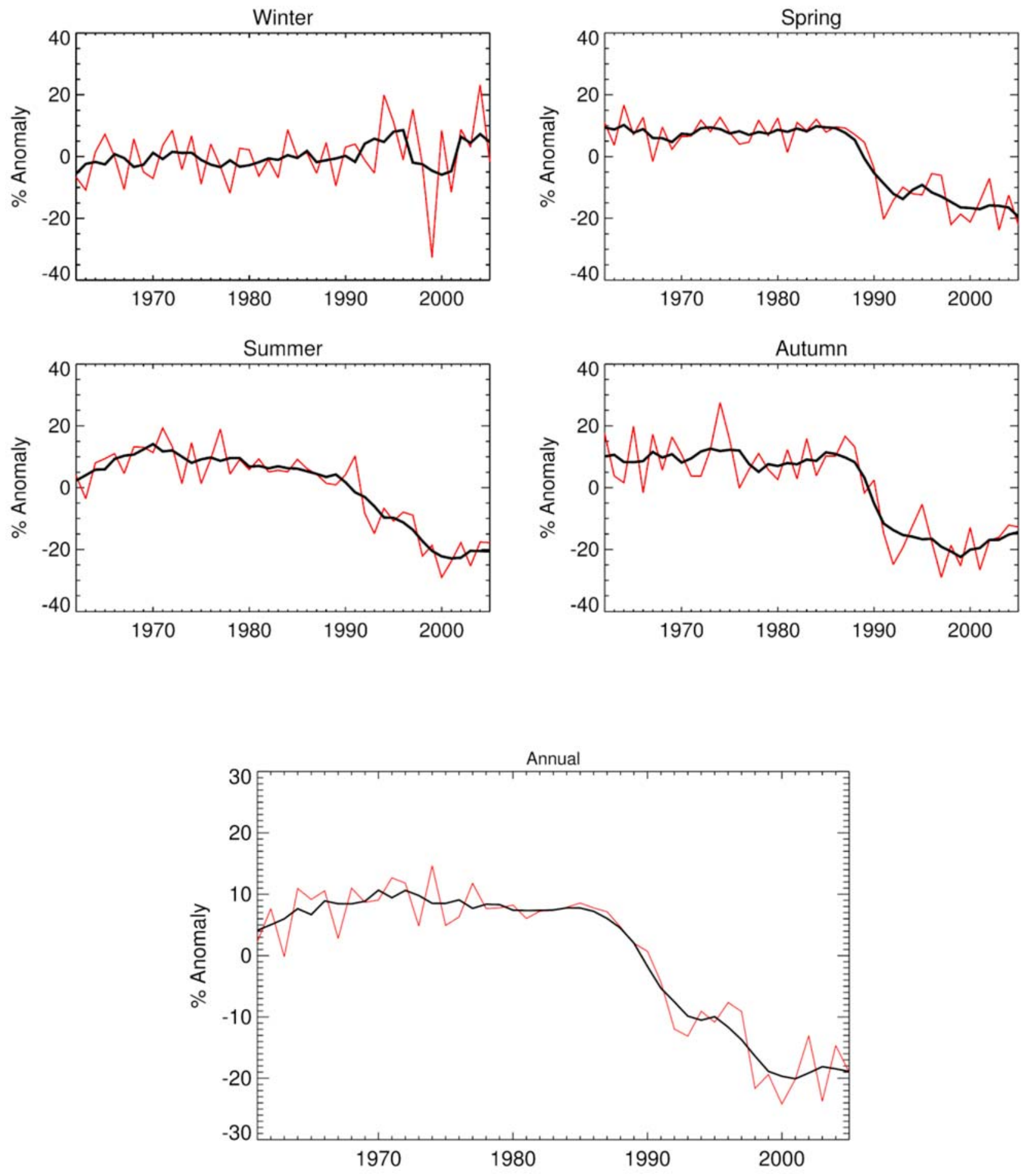

Figure 9. As in Figure 4 but for the Arctic region.

[27] In the southwest region shown by the site of Saint Paul Island, the changes in DSW during the late 1970s were clearly seen in the winter (Figure 13) and autumn time series. Also, the magnitude of the cloud cover for this shift was greater than the DSW but there was still a high significant correlation of -0.71 and -0.92 for the winter mean smoothed and unsmoothed time series, respectively. The distinct change that occurred in 1989 was also evident but only in the spring and summer mean time series. During
1999 all the time series showed this abrupt change in cloud cover except the winter mean series.

[28] The west region includes the site of Kotzebue, with the change in the late 1970s only seen in the annual series (Figure 14). The other turning points occurred during 1989 and 1998, which were easily noticeable and were among the clearest and strongest signals from all the regions. It was also important to note that there was an exceptionally good agreement during 1998 between the DSW and the cloud 
Table 1. Regional Alaskan Trends of Annual and Seasonal Means From Two Periods, 1961-1975 and 1977-1991, of All-Sky Downward Surface Solar Radiation Based Upon Linear Least Squares Regression ${ }^{a}$

\begin{tabular}{|c|c|c|c|c|c|}
\hline Region & Annual $\left(\% \mathrm{yr}^{-1}\right)$ & Winter (DJF) $\left(\% \mathrm{yr}^{-1}\right)$ & Spring (MAM) $\left(\% \mathrm{yr}^{-1}\right)$ & Summer (JJA) $\left(\% \mathrm{yr}^{-1}\right)$ & Autumn (SON) $\left(\% \mathrm{yr}^{-1}\right)$ \\
\hline Southeast & $0.50 /-0.98$ & $1.67 /-1.07$ & $0.00 /-\mathbf{0 . 9 4}$ & $0.37 /-\mathbf{0 . 9 7}$ & $1.13 /-0.98$ \\
\hline South-central & $0.11 /-0.23$ & $\mathbf{1 . 0 5} /-0.32$ & $-0.19 /-0.34$ & $0.31 / 0.00$ & $-0.08 /-\mathbf{0 . 6 7}$ \\
\hline Southwest & $0.61 /-1.25$ & $1.14 /-0.56$ & $0.72 /-1.00$ & $0.55 /-1.50$ & $0.79 /-1.45$ \\
\hline West & $0.83 /-0.48$ & $1.21 /-0.19$ & $0.53 /-\mathbf{0 . 6 9}$ & $\mathbf{0 . 9 1} /-0.20$ & $0.95 /-\mathbf{0 . 8 8}$ \\
\hline Interior & $\mathbf{0 . 6 9} /-0.13$ & $\mathbf{0 . 8 8} /-0.35$ & $\mathbf{0 . 7 4} /-0.21$ & $\mathbf{0 . 6 6} /-0.01$ & $0.62 /-0.32$ \\
\hline Arctic & $0.34 /-\mathbf{0 . 6 5}$ & $0.31 / 0.37$ & $0.00 /-\mathbf{0 . 9 5}$ & $0.40 /-\mathbf{0 . 4 4}$ & $0.47 /-0.57$ \\
\hline
\end{tabular}

${ }^{a}$ Bold values indicate significance at the $95 \%$ confidence level. Left-hand values represent the period $1961-1975$, while the right-hand values are from 1977 to 1991.

cover. The correlation was high and significant, especially in summer with a maximum of -0.85 for the smoothed time series.

[29] For the Interior region, which was represented by the Fairbanks site, only the change in 1998 was clearly defined in these time series, especially in the annual, winter (Figure 15), and summer. Again the agreement between the DSW and the cloud cover was high during this change with a maximum significant correlation of -0.80 during the winter mean
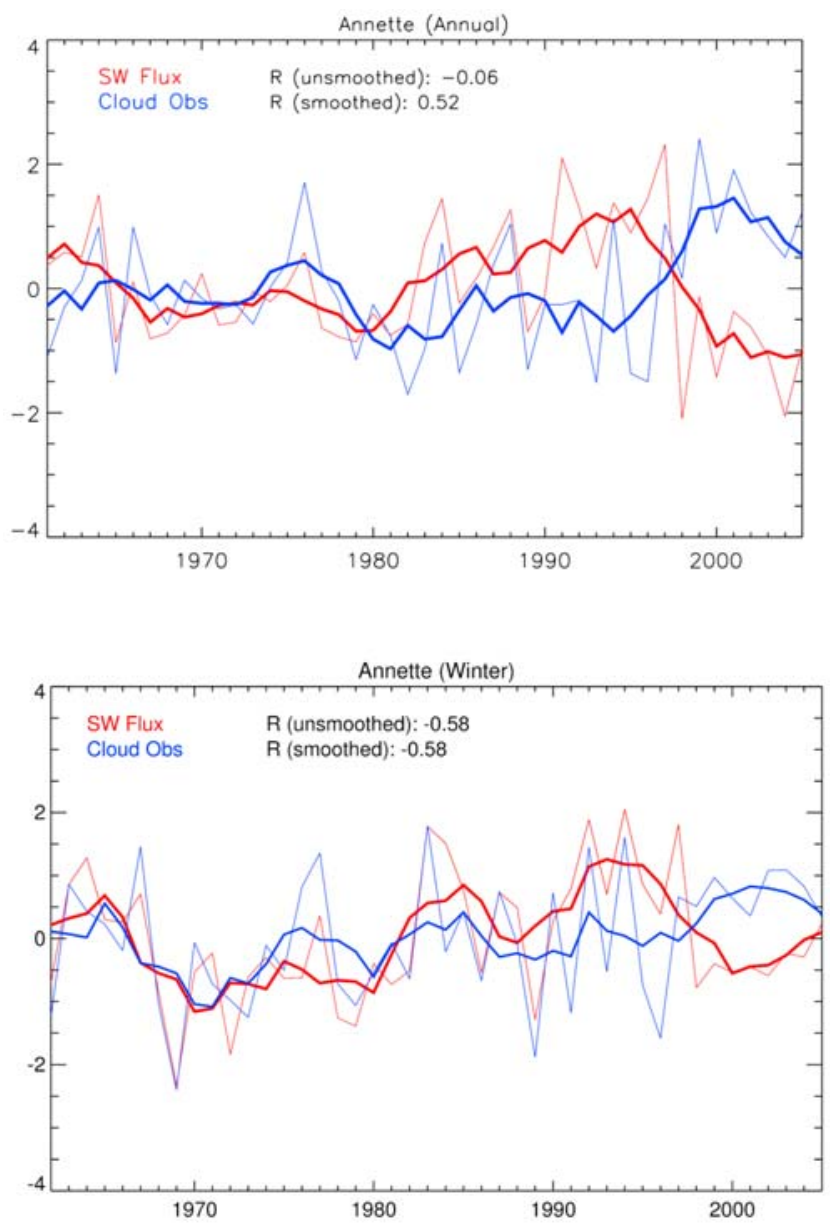

Figure 10. Time series of the opposite of (top) annual and (bottom) winter (DJF) mean model-derived all-sky downward surface shortwave radiation (light red line) and cloud cover observations (light blue line) with smoothed (5 year moving average) (dark blue line) and unsmoothed (dark red line) correlations for Annette. Units are standardized anomalies and are dimensionless. smoothed time series The Arctic site of Barrow did not display the typical variations that were discovered in the other regions; however, the change that occurred in 1998 was evident in the winter time series, which showed good agreement with the DSW at this time (Figure 16).

[30] Trends in cloud cover for all stations were also analyzed (not shown). The greatest changes before and after the shift occurred in sites that represented the south-central region (Anchorage and Talkeetna) followed by the interior and western Alaska. The only location that showed a clear change from a negative to positive trend was the Interior (Fairbanks) during winter with -0.06 and $0.76 \% \mathrm{yr}^{-1}$, respectively. The least amount of changes in cloud cover
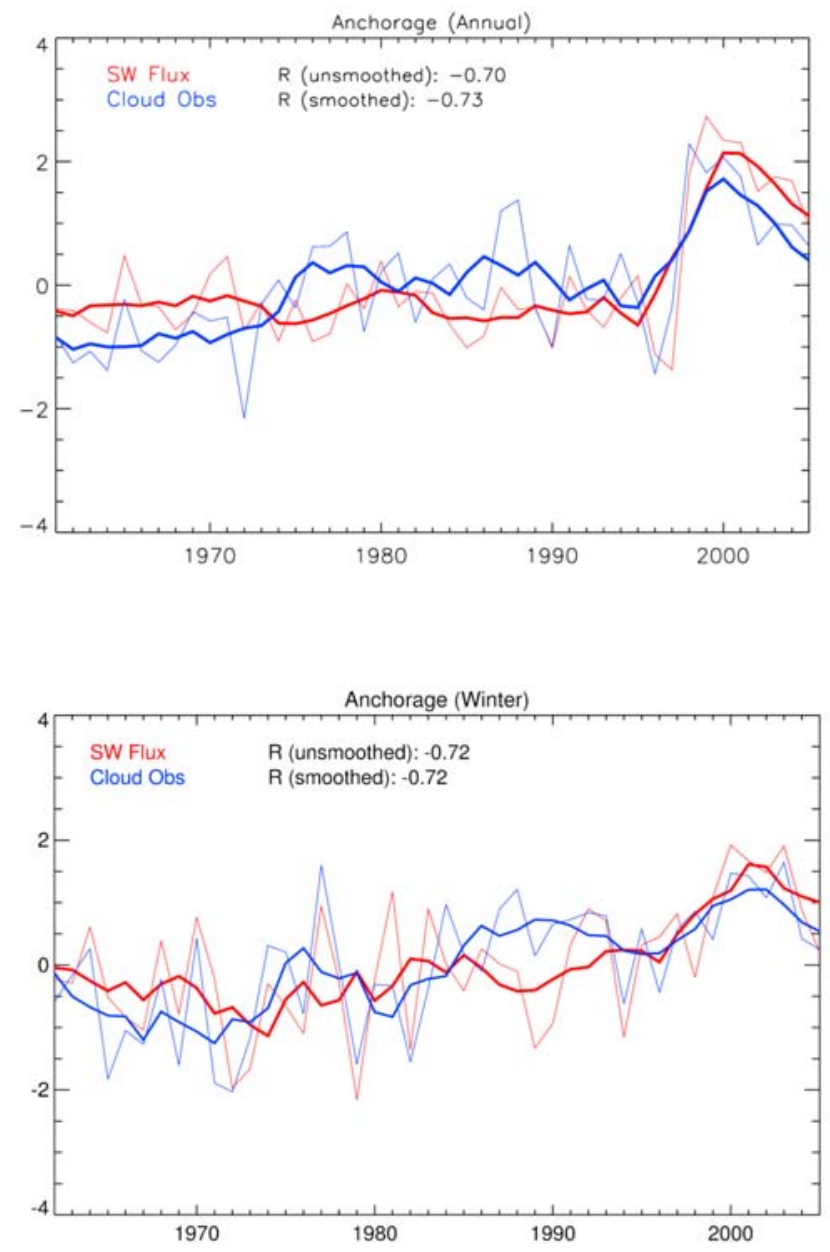

Figure 11. As in Figure 10 but for Anchorage. 

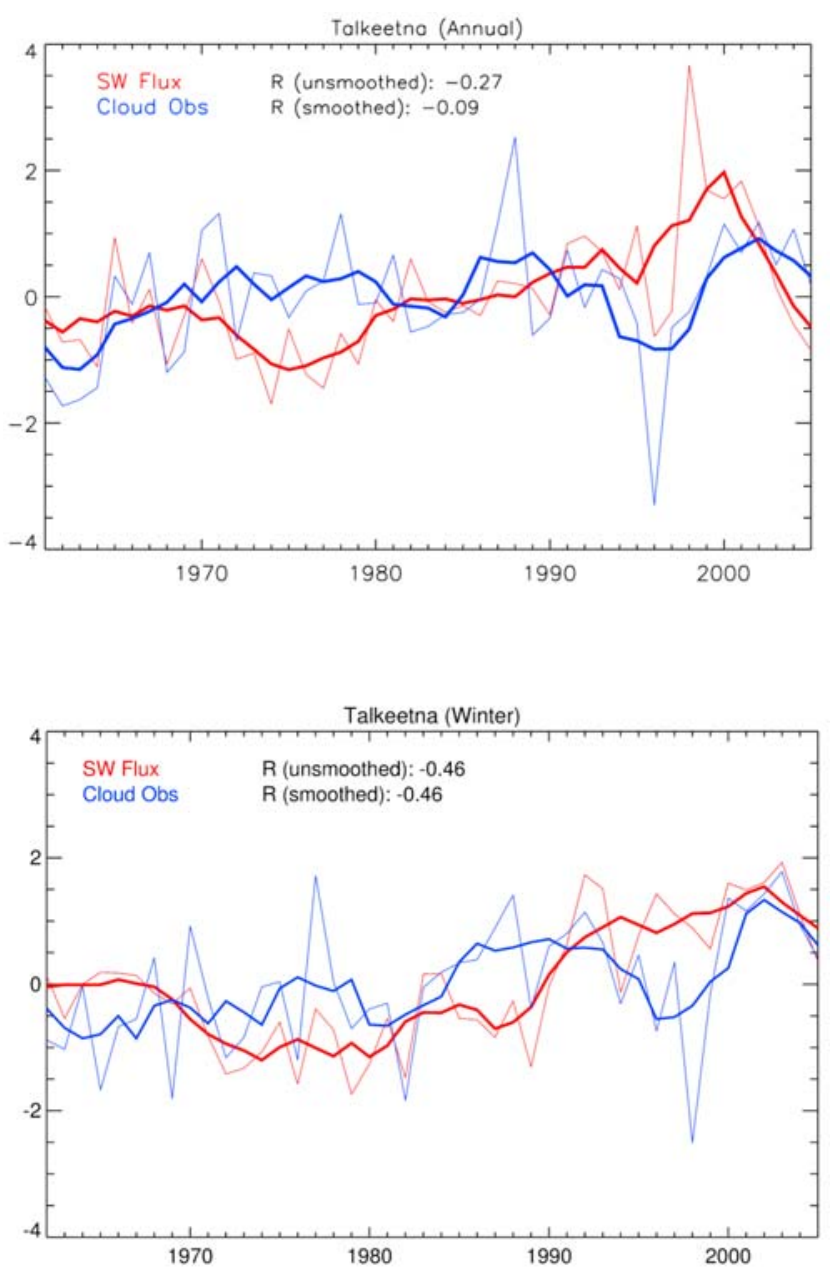

Figure 12. As in Figure 10 but for Talkeetna.

occurred in the southeast, southwest, and Arctic regions where most sites were not statistically significant.

\subsection{Effects From Circulation Patterns (PDO and PNA)}

[31] Figure 17 shows the location of each site analyzed for the correlation between the winter mean DSW and the winter mean PDO/PNA index for the whole series (19612005). Overall the correlation for the DSW and PDO was good to moderate with a maximum and significant value of -0.43 found in Big Delta (interior). The lowest correlations were located in some of the sites in the western region and in Barrow (Arctic), which were not statistically significant. For the PNA, a much stronger relationship in all sites was displayed, except for Saint Paul Island. A maximum value of -0.66 was found in Anchorage (south central) and was statistically significant. Also, in Anchorage the PNA explained $36 \%$ of the winter-to-winter variability in DSW while the PDO and PNA together explained $43 \%$. In Big Delta, for example, the PNA explained $30 \%$ of the winter-towinter variability in DSW and the PNA and PDO explained $30 \%$. Weaker correlations with no significance were found in some of the sites in the western region and in the Arctic; these were the only sites that were not significant.

[32] The correlation between the cloud cover and the PDO/PNA is also displayed in Figure 17. What was noticeable was the increased influence from circulation changes on the cloud cover for all sites except Fairbanks (interior), Bethel (west), and Kotzebue (west). Note that these were locations with the lowest correlations, which were also not statistically significant. Sites contained in the other regions showed higher values of correlation and were statistically significant with a maximum in Anchorage of 0.48 and 0.71 for the PDO and PNA, respectively.

[33] Figure 18 is similar to the previous figure, but represents the correlations computed from 1961 to 1990. This period was chosen in order to determine if changes occurred in the correlations among the different sites. In addition, the end of this period corresponded to one of the minor shifts in the PDO and PNA found in 1989, discussed earlier. Referring to the DSW and the PDO/PNA relationship, a maximum of $-0.63 /-0.78$ occurred in the Kodiak site (southwest) and was statistically significant. Also, as before the PNA relationship with the DSW was much greater for all sites except for Saint Paul Island. Low correlations were found in some of the sites in the western and Arctic regions and were not significant.

[34] The correlations among the clouds and the PDO/PNA in this period were highest in Anchorage (south central) with maximum values of $0.57 / 0.74$. This was followed by the Talkeetna site (south central) with values of $0.55 / 0.70$, which were all statistically significant. Also note the weaker values
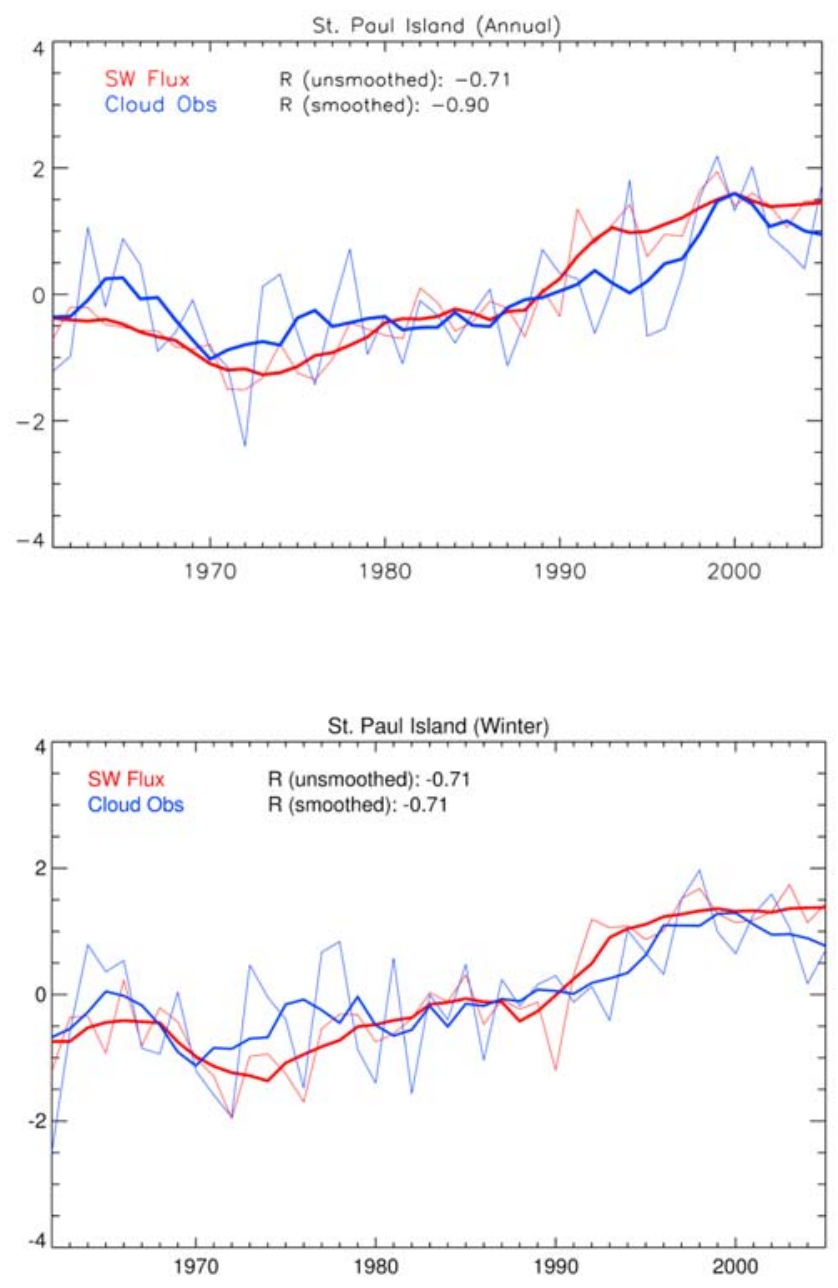

Figure 13. As in Figure 10 but for St. Paul Island. 

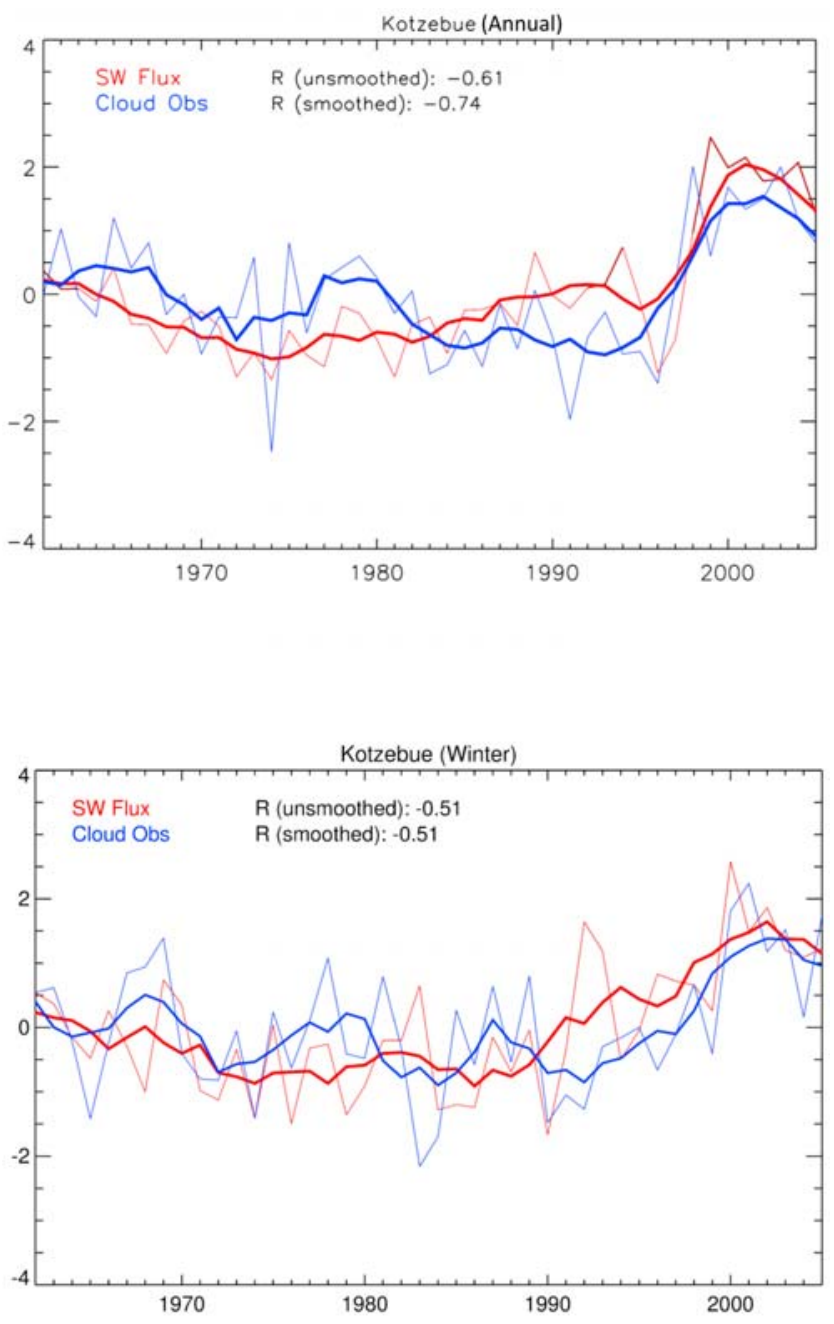

Figure 14. As in Figure 10 but for Kotzebue.

found in Kotzebue and Fairbanks, which were not statistically significant.

\section{Discussion}

[35] A decreasing trend in DSW was found during the second period of the 1976 shift (1977-1992), especially in winter, was seen in all regions of Alaska except in the Arctic. These large changes of the DSW seen in the positive mode (warm) climate regime are in line with the associating changes in other climatological [Graham, 1994; Trenberth and Hurrell, 1994; Zhang et al., 1997; Mantua et al., 1997; Papineau, 2001; Hartmann and Wendler, 2005] and biological variables [Mantua et al., 1997; Hare and Mantua, 2000], which are most affected by the shift. The link that could be made with a decreasing trend of the DSW and these other variables after the shift is an increase in cloud cover, surface temperature, precipitation, and a decrease in sea level pressure and $500 \mathrm{hPa}$ geopotential heights. Some of these variables are now discussed to explain their relationship with the results found from the analyses of the DSW and to give increasing evidence that the PDO in Alaska does have a large effect on these variables, especially in winter. The only cloud cover station whose trends before and after 1976 were significant and consistent with the trends in DSW was located in Fairbanks, during winter. This lack of consistency with the DSW trends in these stations could be due to the larger interannual variability found in the cloud cover, which can influence and change the overall sign of the trend of the time series. Though these cloud cover trends did not agree with the trends found in the DSW, the correlation between them was still high and increased in the low-frequency variability (5 year moving average) compared to the high-frequency variability of the original time series for almost all cloud cover stations. This suggests that cloud cover does play a large role to the changes in DSW.

[36] Surface temperatures in Alaska are either affected directly by SST anomalies that occur in the central and northern North Pacific in coastal areas or are influenced indirectly in other areas of the state by a change in circulation that occurs during a shift in the PDO such as in 1976 [Papineau, 2001]. When surface temperatures are affected indirectly the atmospheric conditions are such that a deeper low forms and brings an increased advection of warm air from the southwest resulting in warmer temperatures in winter [Trenberth, 1990; Papineau, 2001]. In addition, this deepened low-pressure system also creates more cloud cover, which in turn has an effect on the longwave emitted radiation. The longwave emission from the surface
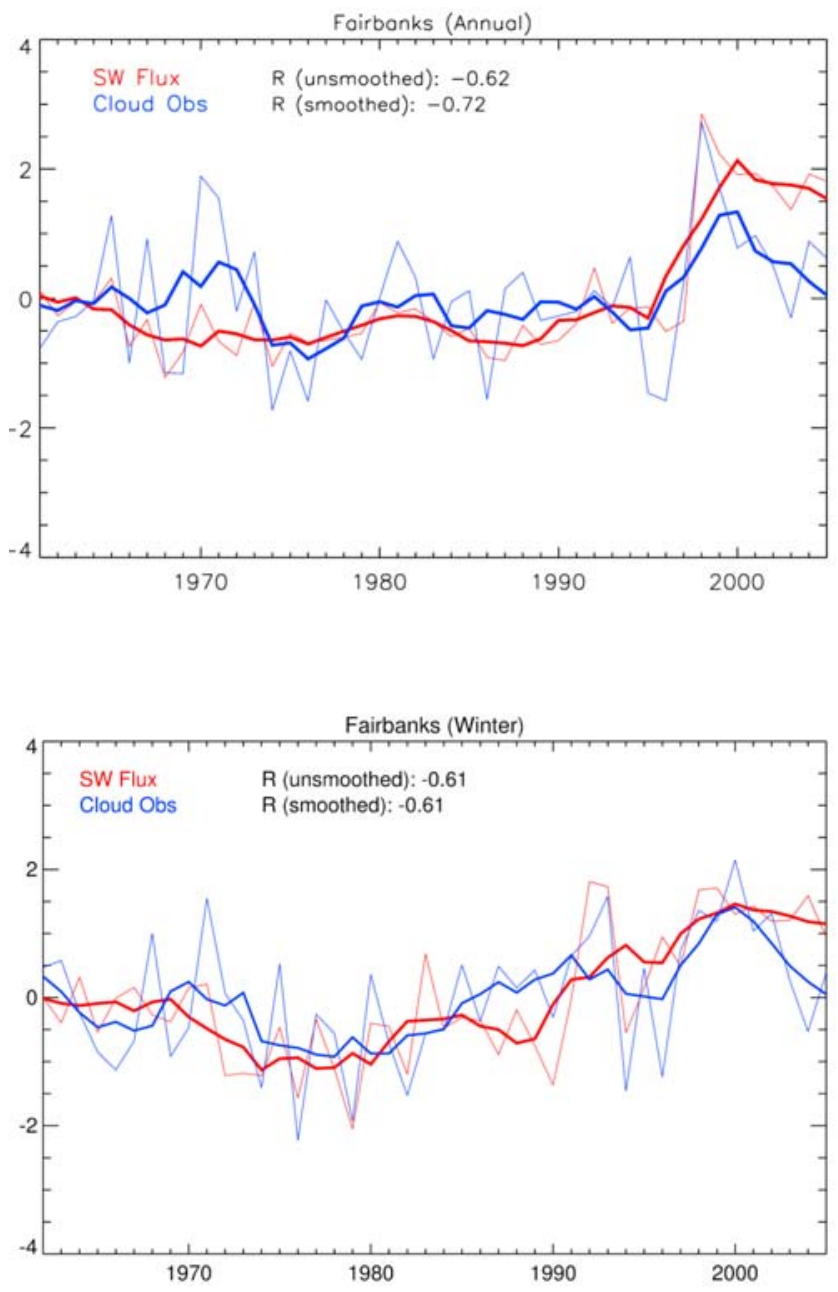

Figure 15. As in Figure 10 but for Fairbanks. 

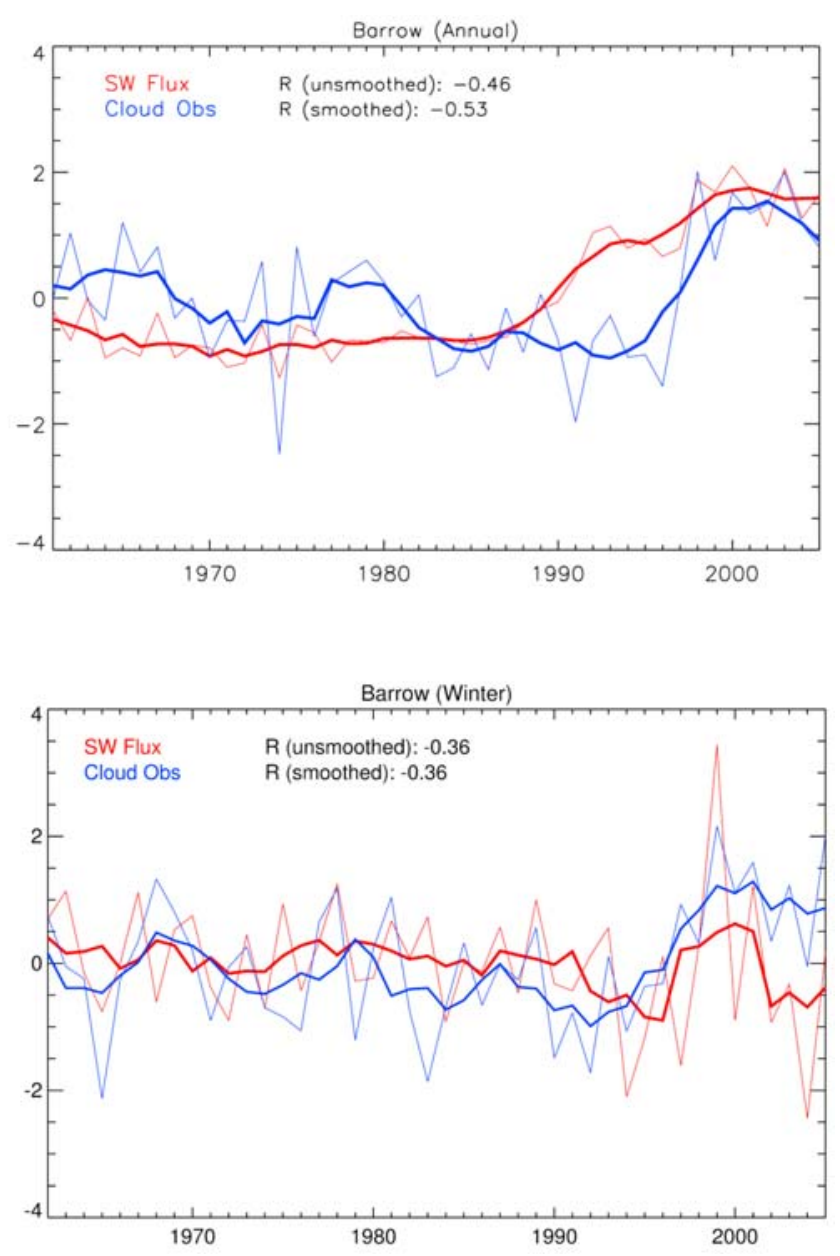

Figure 16. As in Figure 10 but for Barrow.

is also emitted from the clouds, which enhances the surface temperatures [Wang et al., 2001]. Moreover, with a high occurrence of low-level clouds in Alaska [Dissing and Wendler, 1998], the sensitivity of the downward longwave radiation is greatest to cloud cover from these types of clouds [Chiacchio et al., 2002]. Thus, any increase in cloud cover can cause more longwave emission to reach the surface and hence, greater surface temperatures. Because of the low solar elevations and decreased hours of daylight [Hartmann and Wendler, 2005], the DSW has little effect on the temperature in winter in this region. The only link that may exist between these variables is with the total cloud cover, which can affect both.

[37] From the variations that have taken place in these climate variables during 1976, additional shifts have also appeared. These shifts are seen in the winter temperature time series during 1989 and 1998 [Papineau, 2001] as well as in the DSW time series in this study. Moreover, the PDO index became negative for a couple of years during these other shifts in 1989 and 1998. The shifts found in the DSW also only lasted for a couple of years until they became positive again. Other evidence for the 1989 shift is given by Hare and Mantua [2000], where 100 different variables, both climate and biological, are used to assess their changes. As a result there is a strong signal, especially from the biological variables, in which they conclude that an earlier identification of regime shifts is possible from these variables. During 1998 another change is apparent in the PDO index and is stronger than the one in 1989 [Radionov and Overland, 2005]. This is in line with the results found in the DSW time series. Radionov and Overland [2005] find that the cyclonic activity in the Bering Sea increases significantly during this time and even more so than the activity during the regime of 1977-1988. Does this point to a new climate regime? It is proposed by Peterson and Schwing [2003] that the PDO mode may be shifting toward the negative because after the strong El Niño in 1998, many changes occurred in the oceanic, atmospheric, and biological variables late that year. This is in line with the changes seen in the DSW in some of the Alaskan regions where a strong decrease occurs around 1998. Just as it took some time for the 1976 shift to be recognized as a new climate regime with the PDO in its positive phase, it could take some time to determine with certainty whether this additional shift in 1998 points to a negative mode of the PDO.

[38] With a fair amount of evidence and support that the changes in these climate variables are due to a shifting of the PDO in 1976, it is important to also look at how much the climate signal, such as the PDO and the atmospheric circulation, such as the PNA have on the DSW throughout the whole time period. The correlation between the DSW and the PDO during 1961-2005 in winter showed fairly good agreement, especially in the interior region of Alaska. However, it is weaker than the values reported for surface temperatures as given by Zhang et al. [1997], Mantua et al. [1997], Papineau [2001], and Hartmann and Wendler [2005]. The reason for the weaker relationship is, as explained above, due to the DSW being affected indirectly through variations in cloud cover brought about by a shift in the PDO. The PDO as already mentioned is actually a longterm fluctuation of the Pacific Ocean with a signature of either cold or warm SST anomalies in the eastern area. A stronger relationship, however, is found when the DSW is correlated with the PNA index. This result clearly allows an assumption to be made that variations in DSW in the Alaskan winter are primarily influenced by the changes in the atmosphere because the PNA is described with $500 \mathrm{hPa}$ height anomalies. Moreover, in this study as well as in that of Ewen et al. [2008] it was found that the PNA was strongly correlated to the PDO, indicating that the atmosphere follows the SST anomalies in the North Pacific. The circulation resulting from these SST anomalies can be modified by the PDO by changing its frequency and position [Papineau, 2001; Renwick and Wallace, 1996]. As a result, the positive mode of the PDO can cause a higher frequency of the positive phase of the PNA. With more frequent positive PNAs the flow pattern becomes meridional meaning that the Aleutian low, which is deeper than before [Wallace and Gutzler, 1981], becomes now centered over the eastern Gulf of Alaska advecting warm air to the southeast and south-central regions of Alaska. Conversely, when the PNA is negative the Aleutian low becomes centered more in the western part of the Bering Sea with another weaker low in the Gulf of Alaska [Papineau, 2001]. However, during 1977 to 1993, Zhang et al. [1997] find that the frequency of the positive phase of the PNA increases.

[39] With regards to the correlation between the PDO/ PNA with cloud cover, it was found that there exists a 


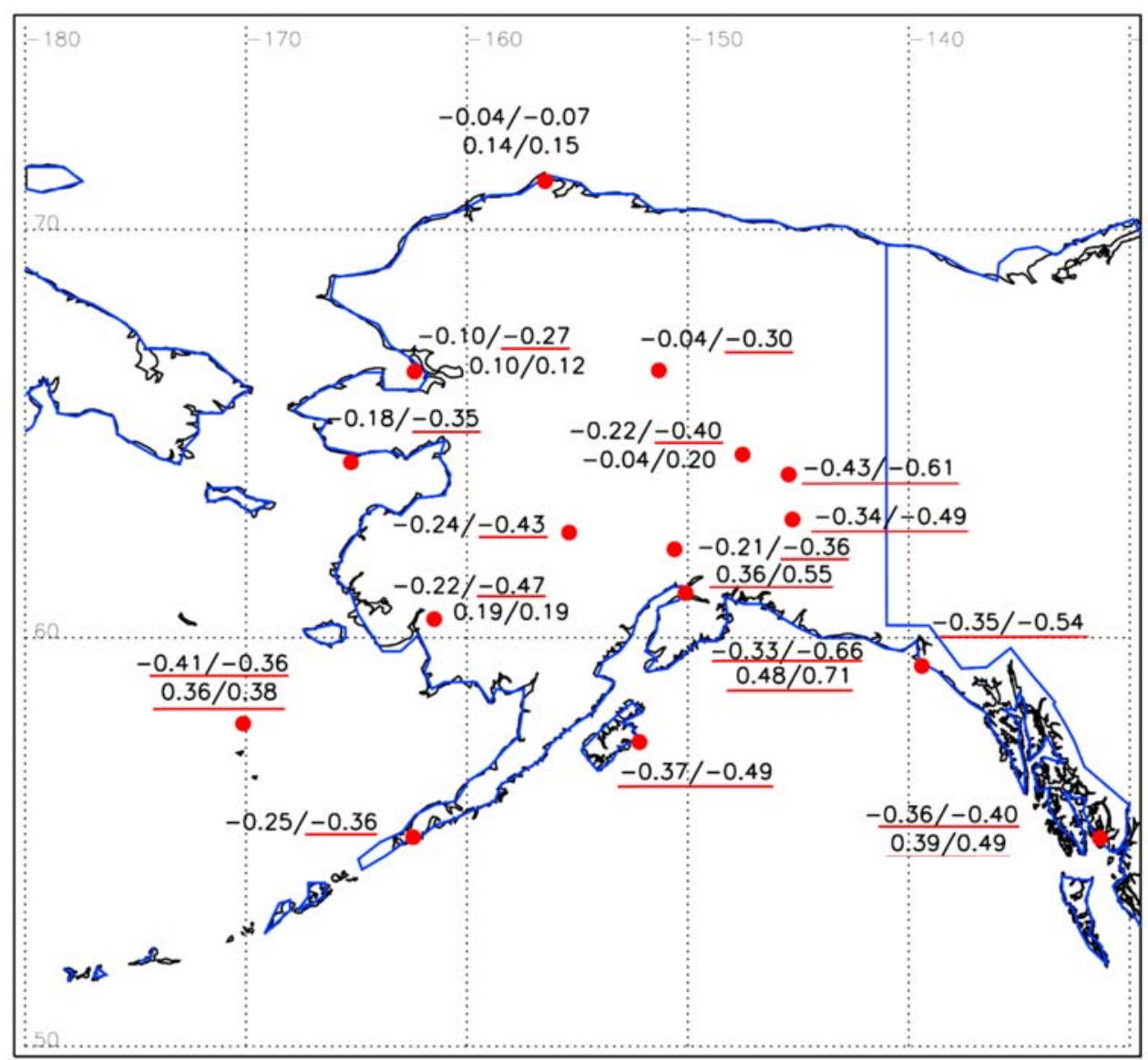

Figure 17. Site-by-site correlation analysis for 1961-2005 between the model-derived all-sky downward surface shortwave radiation (DSW) and the Pacific Decadal Oscillation (PDO)/Pacific North American (PNA) index and between the cloud cover observations and the PDO/PNA index. Upper left values are the comparison with the fluxes and the PDO, and upper right values are with the PNA. Lower left values are the correlations with the cloud cover observations and the PDO, and lower right are the values with the PNA. If no lower correlations are present, then the upper values represent the ones for the fluxes. Correlation coefficients underlined in red are statistically significant at the $95 \%$ confidence level.

stronger relationship than with these circulation indices and the DSW, except for sites within the western and interior regions. The maximum values for the correlation of the PDO/PNA with cloud cover were found in Anchorage (south central), which is in line with the highest correlation found for the DSW and PNA and temperature and PDO [Hartmann and Wendler, 2005]. A higher correlation existed with cloud cover and the PNA than with the PDO, but overall it was still weaker than the relationship that the temperature has with the PDO because cloud cover was also found to be indirectly affected by this climate shift.

[40] When the DSW and the cloud cover were correlated with the PDO and PNA from 1961 to 1990, similar characteristics were found but overall this period showed a much stronger correlation than during 1961-2005. This may be due to an additional higher-frequency mode of variability that could be interacting with the PDO, such as ENSO. With the shorter-duration time scale of ENSO, the El Niños and La Niñas are superimposed over the longer PDO cycle, which has an additional effect on the temperature [Papineau, 2001]. In Papineau [2001] it is found that when El Niños occur during the positive phase of the PDO, higher temperatures are reported; however, during a nega- tive PDO there exists below average temperatures. During a La Niña in winter below average temperatures are always found. In addition, the findings of Peterson and Schwing [2003] suggest that the El Niño in 1998 may have strongly influenced the PDO. Taken together, these studies indicate that strong ENSO variability, which affects the PDO, also affects climate variables, including surface temperatures and cloud cover. A strong La Niña also occurred in 1988, and this strong ENSO variability may have influenced the PDO during this period, leading to the shift found in the PDO during 1989. It is also possible that this strong ENSO variability weakened the influence of the PDO on climate variables, including cloud cover and DSW after this period.

\section{Conclusions}

[41] The results shown here for the decadal variations in DSW are dissimilar to the changes displayed in the classical dimming and brightening that have been found from most studies; however, when compared to other climate variables that have been greatly affected by the PDO and PNA, the explanation for the trends in the DSW and the connection found with these other variables become clear. Overall the 


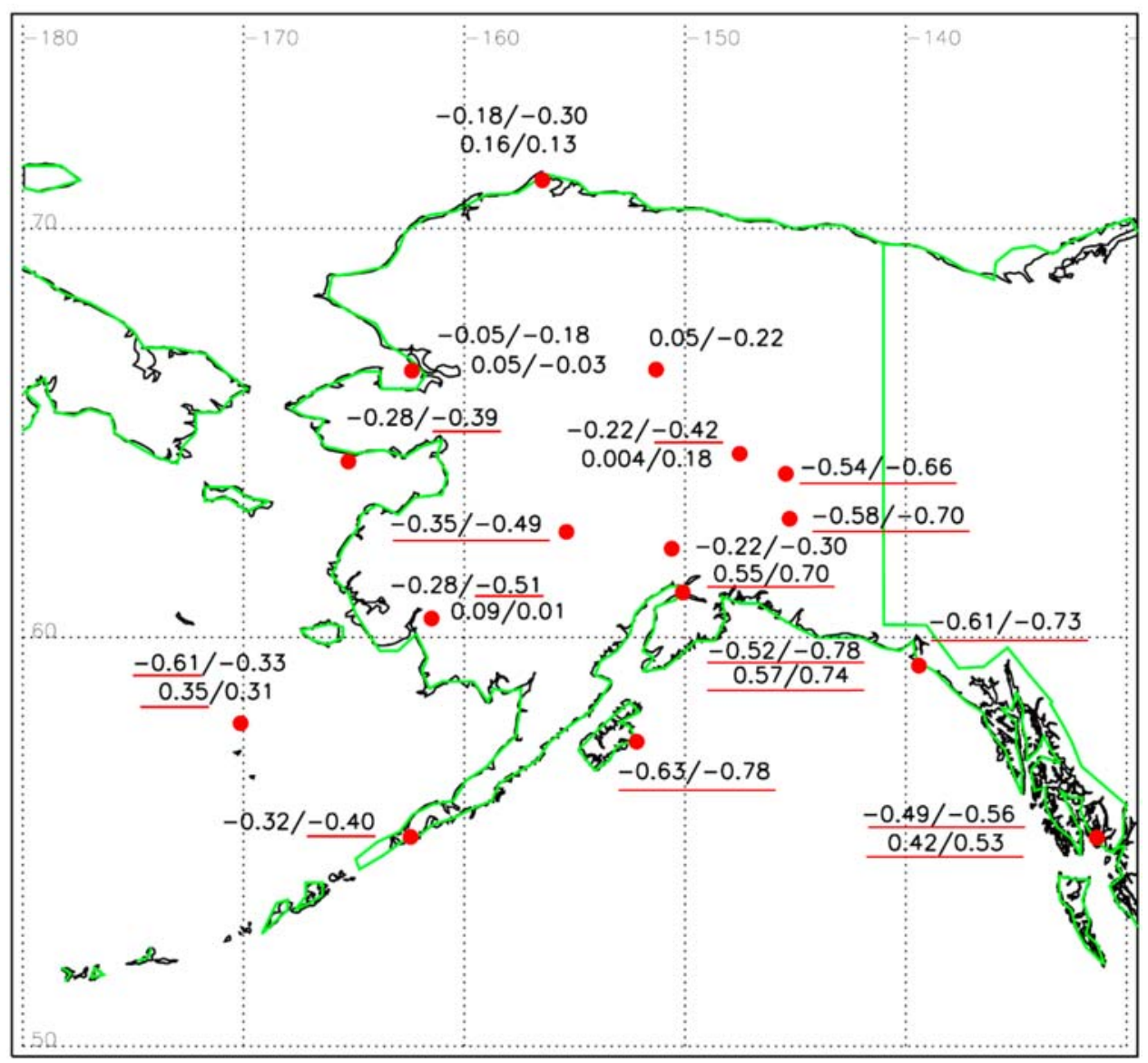

Figure 18. As in Figure 17 but for 1961-1990.

changes of the DSW found in Alaska, in winter in all regions except the Arctic showed an increase from 1961 until about the mid-1970s followed by a sharp decrease until about the late $1990 \mathrm{~s}$. In some cases there was a strong increase after around 1998. In general the same behavior was seen in the cloud cover record, surface temperature, wind speed, and sea level pressure, plus many other nonoceanic and atmospheric parameters. When the PDO was in its positive phase there were additional short periods of a few years when it reversed polarity such as in 1989 and 1998. During these times the DSW as well as other variables were seen to be affected in the same manner.

[42] To have an understanding of the relationship between the DSW and other variables when the PDO is in its positive phase, it becomes important to know the events that are occurring in the ocean-atmosphere system. During this mode of variability, the SSTs in the central North Pacific are anomalously cool with SSTs in the eastern North Pacific (Bering Sea) being anomalously warm. Also, during this positive phase the Aleutian low deepens and shifts toward the east over the Bering Sea. This produces advection of warm moist air over Alaska. With these events in play the storms increase producing more cloud cover over Alaska, which in turn has an influence on the DSW. Thus, these climate variables including DSW are strongly governed by the circulation patterns that also interact with each other, which also have varying frequencies of variability. Compared to the surface temperature and cloud cover the DSW during wintertime had a weaker relationship, but a good to moderate correlation (as high as -0.66) was still shown with the PDO and PNA, particularly in the interior and the south-central regions in winter. Also, up to $43 \%$ in the winter-to-winter variability of DSW in these locations was explained by the PDO and PNA. Other regions than the ones mentioned above where the correlation was found to be lower could be due to the PDO and PNA not acting strongly, which implies that there was not a great influence of cloud cover on long-term changes in DSW. In the Arctic region additional climate modes of variability, such as the Arctic Oscillation (AO) may also be weakening the relationship between the PDO/PNA and DSW.

[43] Another contributing mode of variability that could be interacting with the PDO and PNA was discovered when the DSW and cloud cover is correlated with the PDO and PNA during 1961-1990. The correlation found in almost all regions were stronger compared to the longer period from 1961 to 2005. We attribute the decrease in the latter period to the interference from ENSO, which is a higherfrequency variability that could be dominating the influence of the DSW and clouds and weakening the relationship with the PDO/PNA. The influence of ENSO during this time could be the main cause because this is when the strongest El Niño occurs in 1997/1998. Further study would be needed to decipher the connections between all these climate modes of variability but it is beyond the scope of this work. The results from this study have shown that the 
temporal evolution of the DSW in certain regions of Alaska, especially in winter, may have been driven by these climate modes of variability and cloud cover changes and that other potential contributing factors, such as changes in concentration of aerosols may be playing a lesser role.

[44] Acknowledgments. This research is financially supported by the National Centre of Competence in Climate Research (NCCR Climate) sponsored by the Swiss National Science Foundation. The authors would like to express their gratitude toward Christoph Schaer and Atsumu Ohmura for all their support. We would like to thank Steven Wilcox for providing data from the National Solar Radiation Database (NSRDB) at http:// rredc.nrel.gov/solar/old data/nsrdb/ produced by the National Renewable Energy Laboratory. We thank Martha Shulski for providing cloud data from the Alaska Climate Research Center of the Geophysical Institute, University of Alaska Fairbanks. The PNA indices are from the NOAA Climate Prediction Center (http://www.cdc.noaa.gov/Correlation/pna.data). The PDO index data were obtained from the Joint Institute for the Study of the Atmosphere and Oceans website at http://jisao.washington.edu/pdo/ PDO.latest.

\section{References}

Abakumova, G. M., E. M. Feigelson, V. Russak, and V. V. Stadnik (1996), Evaluation of long-term changes in radiation, cloudiness, and surface temperature on the territory of the former Soviet Union, J. Clim., 9, 1319-1327, doi:10.1175/1520-0442(1996)009<1319:EOLTCI $>2.0$. $\mathrm{CO} ; 2$.

Barnston, A. G., and R. E. Livezey (1987), Classification, seasonality and persistence of low-frequency atmospheric circulation patterns, Mon. Weather Rev., 115, 1083-1126, doi:10.1175/1520-0493(1987)115< 1083:CSAPOL $>2.0 . \mathrm{CO} ; 2$

Blackmon, M. L., and Y. H. Lee (1984), Horizontal structure of $500 \mathrm{mb}$ height fluctuations with long, intermediate and short time scales, J. Atmos. Sci., 41, 961-979, doi:10.1175/1520-0469(1984)041<0961: $\mathrm{HSOMHF}>2.0 . \mathrm{CO} ; 2$.

Bond, N. A., and D. E. Harrison (2000), The Pacific decadal oscillation, air-sea interaction and central North Pacific winter atmospheric regimes, Geophys. Res. Lett., 27, 731-734, doi:10.1029/1999GL010847.

Chambers, L. H., P. K. Costulis, and D. F. Young (2004), Students as ground observers for satellite cloud retrieval validation, paper presented at 13th Conference on Satellite Meteorology, Am. Meteorol. Soc., Norfolk, Va.

Chhak, K., and E. Di Lorenzo (2007), Decadal variations in the California Current upwelling cells, Geophys. Res. Lett., 34, L14604, doi:10.1029/ 2007GL030203.

Chiacchio, M. (2001), The evaluation and improvement of downward longwave flux algorithms in the polar night for the Clouds and the Earth's Radiant Energy System (CERES) program, M.S. thesis, 86 pp., Dep. of Environ. Sci., Rutgers State Univ. of N. J., New Brunswick.

Chiacchio, M., and M. Wild (2010), Influence of NAO and clouds on longterm seasonal variations of surface solar radiation in Europe, J. Geophys. Res., doi:10.1029/2009JD012182, in press.

Chiacchio, M., J. A. Francis, and P. W. Stackhouse Jr. (2002), Evaluation of methods to estimate the surface downwelling longwave flux during Arctic winter, J. Appl. Meteorol., 41, 306-318, doi:10.1175/1520-0450(2002)041< 0306:EOMTET>2.0.CO;2.

Dissing, D., and G. Wendler (1998), Solar radiation climatology of Alaska Theor. Appl. Climatol., 61, 161-175, doi:10.1007/s007040050061.

Dutton, E. G., R. S. Stone, D. W. Nelson, and B. G. Mendonca (1991), Recent interannual variations in solar radiation, cloudiness, and surface temperature at the South Pole, J. Clim., 4, 848-858, doi:10.1175/15200442(1991)004<0848:RIVISR > 2.0.CO;2.

Ewen, T., S. Bronnimann, and J. Annis (2008), An extended Pacific-North American Index from upper-air historical data back to 1922, J. Clim., 21 , 1295-1308, doi:10.1175/2007JCLI1951.1.

Gilgen, H., M. Wild, and A. Ohmura (1998), Means and trends of shortwave irradiance at the surface estimated from global energy balance archive data, J. Clim., 11, 2042-2061.

Gilgen, H., A. Roesch, M. Wild, and A. Ohmura (2009), Decadal changes in shortwave irradiance at the surface in the period from 1960 to 2000 estimated from Global Energy Balance Archive Data, J. Geophys. Res., 114, D00D08, doi:10.1029/2008JD011383.

Graham, N. E. (1994), Decadal-scale climate variability in the tropical and North Pacific during the 1970s and 1980s: Observations and model results, Clim. Dyn., 10, 135-162, doi:10.1007/BF00210626.

Graham, N. E., and H. Diaz (2001), Evidence for intensification of North Pacific winter cyclones since 1948, Bull. Am. Meteorol. Soc., 82, 1869 1893, doi:10.1175/1520-0477(2001)082<1869:EFIONP>2.3.CO;2.
Hare, S. R., and N. J. Mantua (2000), Empirical evidence for North Pacific regime shifts in 1977 and 1989, Prog. Oceanogr., 47, 103-145, doi:10.1016/S0079-6611(00)00033-1.

Hartmann, B., and G. Wendler (2005), The significance of the 1976 Pacific climate shift in the climatology of Alaska, J. Clim., 18, 4824-4839, doi:10.1175/JCLI3532.1

Latif, M., and T. P. Barnett (1996), Decadal climate variability over the North Pacific and North America: Dynamics and predictability, J. Clim., 9, 2407-2423, doi:10.1175/1520-0442(1996)009<2407:DCVOTN $>2.0$. $\mathrm{CO} ; 2$.

Liepert, B. G. (2002), Observed reductions of surface solar radiation at sites in the United States and worldwide from 1961 to 1990, Geophys. Res. Lett., 29(10), 1421, doi:10.1029/2002GL014910.

Liepert, B. G., and G. J. Kukla (1997), Decline in solar radiation with increased horizontal visibility in Germany between 1964 and 1990, J. Clim. 10, 2391-2401, doi:10.1175/1520-0442(1997)010<2391:DIGSRW >2.0 $\mathrm{CO} ; 2$.

Mantua, N., S. Hare, Y. Zhang, J. Wallace, and R. Francis (1997), A Pacific Interdecadal Climate Oscillation with impacts on salmon production, Bull. Am. Meteorol. Soc., 78, 1069-1079, doi:10.1175/15200477(1997)078<1069:APICOW>2.0.CO;2.

Maxwell, E. L. (1998), METSTAT - The solar radiation model used in the production of the national solar radiation data base (NSRDB), Sol. Energy, 62(4), 263-279, doi:10.1016/S0038-092X(98)00003-6.

Miller, A., D. Cayan, T. Barnett, N. Graham, and J. Oberhuber (1994), The 1976-77 climate shift of the Pacific Ocean, Oceanography, 7, 21-26.

Namias, J. (1969), Seasonal interactions between the North Pacific Ocean and the atmosphere during the 1960s, Mon. Weather Rev., 97, 173-192, doi:10.1175/1520-0493(1969)097<0173:SIBTNP>2.3.CO;2.

Ohmura, A., and H. Lang (1989), Secular variation of global radiation in Europe, in IRS '88: Current Problems in Atmospheric Radiation, edited by J. Lenoble and J.-F. Geleyn, pp. 298-301, A. Deepak, Hampton, Va. Papineau, J. (2001), Wintertime temperature anomalies in Alaska correlated with ENSO and PDO, Int. J. Climatol., 21, 1577-1592, doi:10.1002/ joc.686.

Peterson, W., and F. Schwing (2003), A new climate regime in northeast Pacific ecosystems, Geophys. Res. Lett., 30(17), 1896, doi:10.1029/ 2003GL017528.

Pinker, R. T., B. Zhang, and E. G. Dutton (2005), Do satellites detect trends in surface solar radiation?, Science, 308, 850-854, doi:10.1126/ science. 1103159

Radionov, S., and J. E. Overland (2005), Application of a sequential regime shift detection method to the Bering Sea ecosystem, J. Mar. Sci., 62, $328-332$.

Renwick, J. A., and J. M. Wallace (1996), Relationships between North Pacific wintertime blocking, El Niño, and the PNA pattern, Mon. Weather Rev., 124, 2071-2076, doi:10.1175/1520-0493(1996)124<2071: RBNPWB $>2.0 . \mathrm{CO} ; 2$.

Russak, V. (1990), Trends of solar radiation, cloudiness and atmospheric transparency during recent decades in Estonia, Tellus, Ser. B, 42, 206-210.

Sanchez-Lorenzo, A., J. Calbo, and J. Martin-Vide (2008), Spatial and temporal trends in sunshine duration over western Europe (1938-2004), J. Clim., 21, 6089-6098, doi:10.1175/2008JCLI2442.1.

Schweiger, A. J., and J. R. Key (1992), Arctic cloudiness: Comparison of ISCCP-C2 and Nimbus 7 Satellite-derived cloud products with a surfacebased cloud climatology, J. Clim., 5, 1514-1527, doi:10.1175/15200442(1992)005<1514:ACCOIC >2.0.CO;2

Stanhill, G., and S. Cohen (2001), Global dimming: A review of the evidence for a widespread and significant reduction in global radiation with a discussion of its probable causes and possible agricultural consequences, Agric. For. Meteorol., 107, 255-278, doi:10.1016/S01681923(00)00241-0.

Stanhill, G., and J. D. Kalma (1995), Solar dimming and urban heating at Hong Kong, Int. J. Climatol., 15, 933-941, doi:10.1002/joc. 3370150807 .

Stjern, C. W., J. E. Kristjansson, and A. W. Hansen (2009), Global dimming and global brightening-An analysis of surface radiation and cloud cover data in northern Europe, Int. J. Climatol., 29, 643-653, doi:10.1002/ joc. 1735 .

Trenberth, K. (1990), Recent observed interdecadal climate changes in the Northern Hemisphere, Bull. Am. Meteorol. Soc., 71, 988-993, doi:10.1175/1520-0477(1990)071<0988:ROICCI $>2.0 . C O ; 2$.

Trenberth, K., and J. Hurrell (1994), Decadal atmosphere-ocean variations in the Pacific, Clim. Dyn., 9, 303-319, doi:10.1007/BF00204745.

Walker, G. T., and E. W. Bliss (1932), World weather V, in Memoirs of the Royal Meteorological Society, vol. 4, pp. 53-84, R. Meteorol. Soc., London.

Wallace, J. M., and D. S. Gutzler (1981), Teleconnections in the geopotential height field during the Northern Hemisphere winter, Mon. Weather 
Rev., 109, 784-812, doi:10.1175/1520-0493(1981)109<0784:TITGHF> 2.0.CO;2.

Wang, S., Q. Wang, R. E. Jordan, and P. O. G. Persson (2001), Interactions among longwave radiation of clouds, turbulence, and snow surface temperature in the Arctic: A model sensitivity study, J. Geophys. Res. 106(D14), 15,323-15,333, doi:10.1029/2000JD900358.

Wilcox, S., et al. (2007), National Solar Radiation Database 1991-2005 Update: User's Manual, Natl. Renewal Energy Lab., Golden, Colo.

Wild, M. (2009), Global dimming and brightening: A review, J. Geophys. Res., 114, D00D16, doi:10.1029/2008JD011470.

Wild, M., H. Gilgen, A. Roesch, A. Ohmura, C. Long, E. Dutton, B. Forgan, A. Kallis, V. Russak, and A. Tsvetkov (2005), From dimming to brightening: Decadal changes in solar radiation at the Earth's surface, Science, 308, 847-850, doi:10.1126/science.1103215.
Zhang, Y., J. Wallace, and D. Battisti (1997), ENSO-like interdecadal variability: $1900-93$, J. Clim., 10, 1004-1020, doi:10.1175/15200442(1997)010<1004:ELIV>2.0.CO;2.

E. Arabini, Department of Mechanical and Civil Engineering, University of Modena and Reggio Emilia, Strada Vignolese 905, I-41125 Modena, Italy.

M. Chiacchio, T. Ewen, and M. Wild, Institute for Atmospheric and Climate Science, ETH Zurich, Universitaetsstr. 16, CH-8092 Zurich, Switzerland. (marc.chiacchio@env.ethz.ch) 